\title{
Characterization of a gold tailings with hypersaline pore fluid
}

David Reid $^{1 *}$, Andy Fourie1, and Stephen Moggach²

${ }^{1}$ University of Western Australia, School of Civil, Environment and Mining

Engineering, Perth, Western Australia

${ }^{2}$ University of Western Australia, School of Molecular Sciences and Centre for Microscopy, Characterisation and Analysis, Perth, Western Australia

*Corresponding Author: david.reid@uwa.edu.au

\begin{abstract}
A series of samples obtained from adjacent to piezocone penetration test (CPTu) locations within a gold tailings storage facility were tested to compare the inferred state parameter $\Psi$ from CPTu results to the in situ density and critical state line (CSL) from reconstituted samples, and to assess the effects of salt concentration in the sample pore fluid on mechanical behaviour of the material. Preparation of samples with similar salt concentrations to those measured in situ gave CSLs that compared favourably to estimates of $\Psi$ from the CPTu, in light of measured in situ density. Tests prepared without salt did not tend towards the same CSL as the salt samples, generally being at higher densities both following consolidation and subsequent shearing. These results are consistent with the observed effects of salt on mechanical behaviour in previous testing on clays. The implications and limitations of the testing program are outlined, and the need for further investigation of these issues is emphasised owing to the importance of tailings storage facility perimeter embankment stability.
\end{abstract}

Keywords: CPTu, critical state, salinity, triaxial 


\section{INTRODUCTION}

\section{General}

Characterising tailings suffers from a number of challenges: (i) as an intermediate soil, the consolidation characteristics are often such that partial drainage occurs during a piezocone penetration test (CPTu), (ii) it is often difficult to apply supplementary tests such as the shear vane and full flow penetrometers owing to hard surficial crusts and drainage rates of the underlying material, (iii) undisturbed samples are difficult to obtain, requiring laboratory tests to be conducted on reconstituted specimens, and, (iv) the ability of reconstituted samples to replicate in situ fabric is not yet clear for silty tailings.

Of the issues listed, perhaps the most fundamental is the difference frequently seen between reconstituted and intact specimens of silty tailings (Høeg et al. 2000; Chang et al. 2011) as this raises questions as to the validity of what is often the only practical method to carry out laboratory testing on low plasticity materials - i.e. reconstituted samples. While differences between in situ and reconstituted fabric would be expected to have an effect at low strains (e.g. Shuttle 2006), the work of Høeg et al. and Chang et al. show fabric effects extending to high strains - of such a magnitude that a unique critical state locus (CSL) appears implausible in those comparisons. This observation, in isolation, would then raise questions about the efficacy of what is likely becoming the most commonly adopted-technique to characterise the liquefaction susceptibility of low plasticity silty tailings, which is measuring the state parameter $(\Psi)$ in situ in combination with laboratory testing on reconstituted samples used to refine critical state parameters and CPTuinterpretation for key layers (e.g. Morgenstern et al. 2016). 
The reasons for the observed differences between intact and reconstituted specimens remain unclear. Layering of the intact specimens may play a role indeed, layering in the intact specimens tested by Høeg et al. (2000) was visually apparent. Layering also appears to be evident in the block samples used by Chang et al. (2011) - for example, see photographs presented by Chang (2009). The potentially important effects of layering within a sample, compared to a homogenous sample, were demonstrated by Baziar and Dobry (1995). Further, a recent study of silty tailings, where negligible layering was measured, indicated better agreement between intact and moist tamped reconstituted specimens (Reid et al. 2018b). Another potentially important factor in this context is pore fluid chemistry. Jamiolkowsi (2014) noted that the pore fluid chemistry of the tailings tested by Høeg et al. (2000) included appreciable quantities of salts and other dissolved solids something which would be unlikely to be reproduced using standard sample reconstitution procedures. The work of Chang et al. (2011) included use of flocculants to prepare samples from a slurry. Similar to the effects of salt, addition of flocculants have been shown to result in changes to the elevation and slope of the CSL (Reid and Fourie 2016). Although Chang et al attempted to wash the flocculant from their samples (after preparation), it is unclear how successful this was in obviating the effects of flocculants on mechanical behaviour. Clearly, based on the available evidence, pore fluid chemistry is a factor that cannot be discounted in the assessment of reconstituted sample behaviour. In other words, simply using deionised or tap water for reconstituting specimens may in some circumstances (e.g. saline tailings) produce spurious results. 


\section{Tailings pore fluid effects}

Mineral processing activities rarely use deionised water for material processing. Rather, many tailings slurries contain appreciable quantities of dissolved solids at deposition (Poulos et al. 1985; Fujiyasu and Fahey 2000; Al-Tarhouni et al. 2011; Mundle et al. 2012; Gorakhki and Bareither 2016), with salts most commonly making up a large proportion of the dissolved solids. This may be of importance for laboratory testing of tailings, as there is significant evidence as to the effects of salinity on geotechnical properties, including Atterberg Limits (Bjerrum 1954; Gorakhki and Bareither 2016), compressibility (Yukselen-Aksoy et al. 2008), brittleness and sensitivity (Mitchell and Soga 2005; Helle et al. 2018), and CSL elevation (Wang and Siu 2006). While tailings are often of low plasticity, being derived primarily from the crushing of rock, it is not currently clear below what threshold of plasticity (or other measure) the salt content of the pore fluid would not affect mechanical behaviour.

While the presence of significant dissolved solids within tailings slurries is common globally, in areas of Western Australia process water is often hypersaline owing to the nature of the groundwater used in mineral processing. Further, the already hypersaline conditions at deposition often increase further owing to evaporation and thus desiccation on the tailings beach (Fahey and Newson 1997; Fujiyasu and Fahey 2000; Reid 2015b). The range of values of pore fluid salinity often encountered $(80-200 \mathrm{~g} / \mathrm{L})$ far exceed those typically encountered in geotechnical engineering practice, aside from some unique locations such as isolated portions of the seafloor (e.g. Kay et al. 2005) and around salt wells used for remediation of sensitive clays (e.g. Helle et al. 2017). Hypersaline conditions mean that the potential effects of salt extend beyond changes to fabric and clay mineralogy. In 
addition, it must be recognised that many soil mechanics phase relationships based implicitly on a liquid Specific Gravity of unity are inapplicable (Imai et al. 1979; Noorany 1984; Kay et al. 2005; Mundle et al. 2012). This can result in erroneous measures of density and water content, for example.

As noted previously, reconstitution procedures used in typical tailings testing often do not consider the chemistry of the in situ tailings pore fluid. This may have significant effects on the relevance of the resulting reconstituted test results, as speculated by Jamiolkowsi (2014). It is noted that even in Western Australia tailings practice, where hypersaline pore fluid (in situ) is common, salinity or quantity of dissolved solids are rarely considered in laboratory testing. The potential limitations of not explicitly considering salinity in reconstituted testing of tailings are investigated in this paper.

\section{Purpose of this study}

This study presents the results of a geotechnical investigation of a gold tailings storage facility (TSF) which features many of the characteristics previously described, including hypersaline pore fluid. One of the primary goals of the investigation was to assess the in situ state parameter, $\Psi$, from locations below the phreatic surface, and the mechanical behaviour of the tailings as a function of $\Psi$. To this end, fixed piston samples were obtained from adjacent to CPTu probes to provide material for reconstituted laboratory testing. Techniques were then developed to test the reconstituted samples at the same salinity as in situ, and assess if such efforts resulted in better agreement with $\Psi$ inferred from the CPTu and from measurement of in situ gravimetric water content (GWC) of the samples.

\section{GEOTECHNICAL INVESTIGATION}




\section{Site Description}

The site relevant to this study consists of two cells (or paddocks) in an upstreamraised gold TSF in the Goldfields region of Western Australia. Testing of surficial reconstituted and tube samples from this TSF was previously outlined by (Reid $2015 b)$, including discussion on salinity and early attempts to manage this pore fluid in testing. Similar to many tailings in the region, at deposition the tailings process water is hypersaline. The total dissolved solids (TDS) measured at the TSF decant ponds ranged from 60 - $100 \mathrm{~g} / \mathrm{L}$ depending on climatic conditions (e.g. significant rain events or wet periods result in lower concentrations). As noted subsequently, these slurry TDS values can subsequently accumulate to higher values at the surface of the tailings in areas where desiccation is occurring and a salt crust forms. The dissolved solids consist largely of sodium chloride salt (77 - $79 \%$ by mass), and are therefore referred to as "salts" where discussed subsequently in this paper. The quantities of various dissolved solids as measured in a decant pond are given in Table 1. The relative percentages of these solids have been found to remain relatively constant at different sampling times, while the total TDS varies seasonally within the range previous indicated.

\section{CPTu interpretation and sampling}

The geotechnical investigation involved a series of CPTu probes with dissipation tests, shear wave velocity measurement, and piston sample recovery using samplers deployed from the CPTu rig. Results from two CPTu probe locations on the TSF beach are discussed in this paper (referred to as CPTu 1 and 2), where a series of piston samples were recovered within a $5 \mathrm{~m}$ lateral distance from target depths 
identified during CPTu probing. These piston samples were sealed on site and used for laboratory testing as described subsequently.

The results of CPTu 1 and CPTu 2 are presented in Figure 1 as normalised tip resistance $Q$, Friction Ratio $\left(F_{r}\right)$, pore pressure response $\left(u_{2}\right)$, and the equilibrium pore pressure $\left(u_{0}\right)$ profile inferred from dissipation testing. The depth range for samples taken adjacent to the probes are indicated against the probe results (as a grey horizontal band) along with the sample identifier used throughout the paper for each sample.

Also shown on Figure 1 are "screening level" estimates of $\psi$ based on the methods outlined by Plewes et al. (1992) and Been and Jefferies (1992). Both screening methods were applied to the tailings considered here owing to the inherent uncertainty in how each method attempts to correlate compressibility to CPTu data (Reid 2015a). The results from these methods are not shown at depths above the likely extent of saturation, as suction can affect CPTu results in ways not accounted for by these (or most other) interpretation methods (Pournaghiazar et al. 2013; Yang and Russell 2015). It is emphasised that this study focussed on conditions below the phreatic surface, as this is where susceptibility to liquefaction is most prevalent. We did not extend the study to the unsaturated zone (i.e. above the phreatic surface) because of the relative lack of liquefaction susceptibility of unsaturated tailings compared with that from below the phreatic surface.

Dissipation tests carried out both above and below the sample depths at CPTu 1 and 2 gave $t_{50}$ values ranging from 10 to $15 \mathrm{~s}$, suggesting partially drained penetration conditions (DeJong and Randolph 2012). Therefore, improved $\Psi$ interpretation methods for drained (Shuttle and Jefferies 1998; Ghafghazi and Shuttle 2008) and 
undrained (Shuttle and Cunning 2007; Shuttle and Jefferies 2016) conditions were inapplicable.

Interpretation of CPTu results was based on a bulk unit weight of $19 \mathrm{kN} / \mathrm{m}^{3}$, pore fluid Specific Gravity ( $\left(\mathrm{SG}_{\text {fluid }}\right.$ ) of 1.09 , and an assumed geostatic stress ratio $K_{0}$ of 0.7. The measures used to obtain $S_{\text {fluid }}$ are discussed below. With respect to assumed $K_{0}$, although it is common for laboratory samples with monotonically increasing consolidation stresses to exhibit a $K_{0}$ more consistent with Jaky's formula (e.g. Northcutt and Wijewickreme 2013), an upstream-raised TSF in an arid region undergoes repeated cycling of phreatic level owing to seasonal variations. Such cycling of vertical effective stresses results in an increase of $K_{0}$ (Youd and Craven 1975; Zhu and Clark 1994) over time - an observation that forms the primary basis for typical recommendations to apply higher $K_{0}$ in $\Psi$ interpretation in some hydraulic fills (Jefferies and Been 2015).

\section{Inferred effects of desiccation}

As noted previously, the deposition at the TSF investigated as part of this study is managed such that significant episodes of desiccation occur, prior to eventual rewetting of the tailings at depth. Therefore, it is of relevance to assess the potential for desiccation-induced overconsolidation and/or the potential development of soil structure as a result of deposition practices. The results of CPTu 1 and 2 at the sampling depth locations are summarised in Table 2 in terms of (a) in situ vertical effective stress, (b) OCR inferred through the methods outlined by Mayne (2014), (c) $K_{\mathrm{G}}$, a measure of potential soil structure proposed by Schneider and Moss (2011), interpreted based on the methods outlined by Robertson (2016), and (d) average $\Psi$ based on the method of Plewes et al. (1992). 
The results suggest a decreasing OCR with increasing vertical effective stress, which is consistent with the stress history of the samples which likely involved desiccation. Indeed, the implied desiccation-induced preconsolidation stress of 300 $400 \mathrm{kPa}$ suggested by the results in Table 2 is consistent with the general magnitude of preconsolidation stresses inferred through testing of a desiccated surficial block sample of gold tailings that was rewet during laboratory testing (Reid et al. 2018a). Similarly, $\Psi$ is seen to increase (i.e. become more contractive) with increasing OCR, which represents a logical trend (e.g. Mayne et al. 2017)

With respect to assessing the structure of the soils, all depth ranges have $K_{G}$ values below the approximate threshold value of 330 indicating structured soils proposed by Robertson (2016). However, there is a trend of increasing $K_{G}$ with OCR, which is consistent with the general trends indicated by Robertson.

\section{LABORATORY METHODS}

\section{Tube sample measurements}

As the tailings were likely to be of low plasticity, and had been driven a distance of over $600 \mathrm{~km}$ to the laboratory, it was assumed they would be significantly disturbed. This was consistent with visual inspection of the samples when tubes were opened, which often had free liquid present above the tailings owing to densification - a common issue in low plasticity silts and clays, even when sampled and transported with care (e.g. Mohajeri and Ghafghazi 2012). Owing to this disturbance, upon arrival in the laboratory they were extruded in their entirety into large trays, and dried in a cool oven $\left(\sim 50^{\circ} \mathrm{C}\right)$. They were then mixed thoroughly in individual sample bags. A small subsample was taken from each bag for further drying in a hot oven $\left(\sim 105^{\circ} \mathrm{C}\right)$. The salt from this subsample was removed by repeatedly washing with 
deionised water. It was then dried again in the hot oven. This allowed the ratios of water, salt, and solids for both the original sample and the sample after cool oven drying to be calculated, enabling calculation of in situ TDS values as shown in Table 3. After completion of this process, the material from each tube at a given sample location and depth range was used to provide a single batch for subsequent reconstituted testing. These batches represent the Samples $A, B$, and $C$ referred to in this paper. Included in Table 3 are the sample index properties, with Atterberg Limits and SG of solids obtained from samples with salt removed through washing. X-ray $(\mathrm{XRD})$ diffraction testing was also carried out to identify the mineralogy of the samples, with results outlined in Figure 2 and Table 4. The XRD results suggest nearly identical dominant minerals in the three samples, with Quartz most prevalent followed by Muscovite and Dolomite.

Although the process outlined previously provides an indication of TDS, SG $_{\text {fluid }}$ is required to enable calculation of void ratio when the concentration of dissolved solids is high. It was thought likely that owing to the prevalence of sodium chloride salt in the pore fluid that the relationship between TDS and $\mathrm{SG}_{\text {fluid }}$ of sodium chloride in water would be reasonable for use. To check this hypothesis, samples of fluid obtained from the decant pond at two different times were compared to the sodium chloride TDS-SG fluid relationship as outlined in Figure 2. Given the good correlation, this relationship was used in the calculation of $\mathrm{SG}_{\text {fluid }}$ throughout this paper.

The void ratios calculated for some of the tubes using the techniques outlined above are included in Table 3. Tube sample void ratios were calculated for each sample location that showed the highest sample recovery rate. This was done because loss of sample might preferentially result in loss of liquid or solids during tube recovery from depth (although the tubes had clearly remained well-sealed during subsequent 
transport, after sealing). The void ratios calculated in this manner were consistent at the different sample locations.

It is emphasised that the TDS measured for each sample exceeded the range observed within the decant ponds at the TSF. This suggests that in the areas of the beach where the tube sample material was deposited and dried, significant salt accumulation occurred owing to the drying process. This is consistent with similar findings for TSFs in the Goldfields region of Western Australia and at the "current" surface of this TSF (Reid 2015b). It may also, as discussed subsequently, provide an indication of the condition of the material after deposition - i.e. the amount of drying-induced densification prior to placement of the next layer of tailings.

\section{Triaxial test preparation}

Triaxial specimens were prepared using a relatively "standard" procedure for critical state testing of tailings, as outlined by Jefferies and Been (2015), and which is also frequently used in current tailings practice (e.g. Morgenstern et al. 2016). This method involves a sequence where (i) samples are prepared in a split mould using the undercompaction method (Ladd 1978) on oversized lubricated end platens, (ii) loose specimens are then saturated under low effective stresses, (iii) shearing is carried out under either drained or undrained conditions to high strains in order to determine critical state conditions over a wide range of mean effective stresses, and, (iv) samples are frozen after testing to allow accurate GWC measurement. The specimens tested in this study were prepared in eight layers, with nominal initial height of $124 \mathrm{~mm}$ and diameter of $62 \mathrm{~mm}$. Further, a few additions to this procedure were developed in an attempt to produce reconstituted samples with the same salinity as in situ, as discussed subsequently. 
The triaxial specimens were prepared from the batches of material previously prepared, which were at a GWC of approximately $10 \%$ - a consistency that is suitable for moist tamping preparation. It is noted that in this state, the salt within the water that remained in the dried material was at saturation level, with excess salts present as crystallised solids. It was initially intended to test the specimens at the in situ TDS value (which were all lower than the likely approximate saturation concentration of $357 \mathrm{~g} / \mathrm{L})$, as it was unclear what affect TDS may have on mechanical behaviour. Therefore, after moist tamping the specimens in eight layers, a quantity of deionised water as necessary to give a resulting TDS for the triaxial specimen equal to in situ conditions was used as the initial flushing water. At the end of flushing of this quantity of deionised water, air bubbles were still seen to be emerging from the top of the specimens, indicating further addition of fluid would be useful to promote saturation (prior to back pressure application). At this point, a toxic interface chamber was connected to the back pressure pump, so subsequent flushing and back pressure saturation activities would not bring hypersaline pore fluid into contact with the pressure pump itself (e.g. Pineda et al. 2016).

In an attempt to maintain the sample TDS constant while adding more fluid, further flushing fluid was prepared to the same TDS as the target value using sodium chloride salt. Although such fluid would differ slightly in constituents to the in situ material, the use of such "synthetic" pore fluid has been applied previously with apparently reasonable results (Pineda et al. 2016). Further, as shown subsequently, used of this synthetic pore fluid had minimal effect on the ratio of different ions typically considered most important to mechanical behaviour.

Once bubble formation ceased under the application of synthetic pore fluid, back pressure saturation procedures commenced, again using the same synthetic pore 
fluid used as the back pressure fluid. After these procedures, a minimum $B$ value of 0.96 was achieved in all tests. As noted subsequently, it was observed that this process resulted in final sample TDS values somewhat higher (15-20\%) than target for Samples A and B. It was thought that application of additional synthetic flushing pore fluid may have been causing the discrepancy, as it could conceivably force some deionised water through the specimen prior to having fully dissolved crystallised salts. This would be more likely if a "channel" of lower salinity fluid began to form through the sample, for example. As such, tests on Sample C were undertaken without additional flushing following the deionised flushing stage, and generally gave final TDS values closer to target values.

It is noted that carrying out $\mathrm{CK}_{0} \mathrm{U}$ tests requires an accurate measurement of sample diameter after saturation. However, for loose silty materials prepared unsaturated, this is not possible using conventional means (during the test) as saturation collapse is significant and unlikely to be isotropic (e.g. Sladen and Handford 1987). Indeed, it is this issue that is the primary rationale for the use of soil freezing to measure endof-test sample density. In this study, in order to obtain accurate dimensions after saturation, the cell and back pressure were slowly reduced to 0 and $-25 \mathrm{kPa}$, respectively. The triaxial cell was then emptied and removed, enabling remeasurement of the sample dimensions. Although re-application of back pressures after this re-measurement did still cause slight sample deformations, these were very small ( $<0.5 \%$ axial strain), and hence assuming isotropic strains for this process (or indeed excluding them altogether), had negligible impact on the resulting calculated sample diameter for use in $\mathrm{CK}_{0} \mathrm{U}$ consolidation testing interpretation. This sample re-measurement method is similar to techniques adopted by Xu and Coop (2017). 
Following shearing, samples were placed in a freezer after closing valves adjacent to the sample. Frozen samples were initially dried according to standard test procedures, except a glass beaker was used as the drying vessel. Although a particular TDS had been targeted for each specimen, it was not known how accurately this would be achieved. Therefore, use of a beaker allowed both drying in a hot oven and subsequent flushing of the material to determine TDS, to be carried out in the same container. After drying, samples were flushed five times with deionised water to reduce salts to a negligible level, and the mass of solids was again measured by hot oven drying. This method was adopted to assist in developing a relationship between electrical conductivity and TDS for the samples, which can therefore be used on subsequent testing campaigns.

Details of the triaxial tests are summarised in Table 4, including the TDS measured for each sample prepared with high-salt concentrations, calculated from end-of-test measurements. The test numbering system is based on sample type (A, B, C), TDS quantity (HS - high salt, for the tests described in this section), and then numbered sequentially. Therefore, the first test on Sample A of the samples with TDS prepared to resemble in situ conditions is referred to as A-HS-1.

\section{Salt Solubility}

As noted previously, the samples prepared using moist tamping contained significant quantities of crystallised salt. It was therefore important to confirm that the salt would dissolve rapidly during the testing process. If not, the test would effectively be carried out on a three-phase medium consisting of tailings solids, liquor, and crystallised salt. This was clearly undesirable. Scanning electron microscopy with elemental analysis by energy dispersive spectroscopy was carried out on samples 
after initial cool oven drying and mixing - i.e., the sample condition used to prepare moist tamped specimens. This indicated the salt crystals were generally smaller than $25 \mu \mathrm{m}$. This size salt crystal, based on observed dissolution rates of salt under a range of conditions (Stiller et al. 2007), and with the promotion of mixing through back pressure saturation, where pore fluid was forced into voids throughout the specimen, suggests rapid dissolution of the salt. This rate would be such that dissolution would be complete during the back pressure saturation process.

Therefore, the procedures used herein were considered sufficient to ensure testing of a two-phase material. However, although dissolution would be complete, it is acknowledged that it is unclear if complete ionic equilibrium was achieved in the samples prior to the commencement of shearing.

\section{Subsequent Testing}

At the completion of the testing outlined previously, a limited quantity of additional material from Samples A and B remained. Additional tests were therefore carried out to assess the effects of TDS on mechanical behaviour.

In the first additional test type, much of the remaining quantity of material was washed repeatedly in deionised water to produce a sample that contained a significantly reduced TDS - approximately $5 \mathrm{~g} / \mathrm{L}$ (after subsequent preparation and saturation in a triaxial). These tests are referred to as "low-salt" (LS in figure annotations) subsequently, and are assigned test numbers based on a similar system to that discussed previously for high-salt tests. Wet sieving of the washed samples was carried out to ensure no fine-grained particles had been inadvertently lost in the washing process. This process indicated an indistinguishable gradation to the high-salt samples. This low-salt material was then used to prepare two triaxial 
tests using the same moist tamping and general test procedures, one CID and one $\mathrm{CK}_{0} \mathrm{U}$. It is of particular note that in the preparation of these samples it was not possible to produce densities as loose as the high-salt samples. Presumably the presence of crystallised salts throughout the soil matrix enables a looser initial state to be achieved.

A final additional test was carried out on the remaining high-salt material from Sample A (A-Flush-1). The sample was first prepared using the same procedure as used for the four initial high-salt samples that were used to determine the CSL, i.e., the moist tamped material included salt, and the flushing and back pressure processes used the same salty synthetic pore fluid. The only difference in initial sample preparation was the use of a full-sized filter stone rather than a small filter stone within a lubricated end, so as to promote more uniform flushing of water through the specimen.

After saturation, the specimen was consolidated to an isotropic mean effective stress of $251 \mathrm{kPa}$. An additional pressure pump filled with deionised water was connected to the bottom of the sample. A pressure $20 \mathrm{kPa}$ higher than the back pressure was then applied to this additional pump, resulting in flushing of deionised water through the specimen. This was repeated until approximately 12 pore volumes of deionised water had been flushed through the specimen over a period of three weeks. The resulting water exiting the sample at the end of flushing ranged from 2 to $3 \mathrm{~g} / \mathrm{L}$. Both valves were then closed and the sample was sheared undrained.

This flushing test was an attempt to repeat the experiments of Bjerrum and Rosenqvist (1956), who flushed salts out of a clay to develop a sensitive material. 
The primary variation in the experiment in the current study was that all flushing was carried out at elevated pressures close to the back pressure value.

\section{RESULTS}

\section{Salt test results}

The stress-strain and Cambridge plots for all of the tests on salt samples are outlined in Figures 3 - 5. Test details for each triaxial test are summarised in Table 4. Average critical state friction ratio $\left(M_{\mathrm{tc}}\right)$ for each sample is included for reference in the plots, where relevant. Critical state conditions were inferred to occur when deviator stress, mean effective stress, and pore pressure or volumetric strain were undergoing minimal change with strain. Contractive behaviour was seen for all the tests owing to their loose initial state. Stress paths for all of the triaxial tests on highsalt samples for each material are shown in Figure 4, 5, and 6 . The results of the four tests on each sample are seen to provide a consistent CSL. In each case, the power-law fits shown provide slightly improved fits to the data compared to a logarithmic fit, and are therefore used in all subsequent calculations of $\Psi$. The goodness of fit is indicated for each power-law using mean absolute error (MAE).

\section{Comparison to in situ state}

The CSLs outlined in Figure 4 are reproduced in Figure 5, without the test stress paths for clarity. Presented against these CSLs are the following data related to the in situ state of the tailings:

- In situ void ratio results inferred from tube sample measurements GWC, as previously outlined in Table 3. 
- Void ratios calculated based on the CSLs inferred from high-salt samples and the range of $\Psi$ estimated across the tube sample depths, based on the methods of Plewes et al. (1992) and Been and Jefferies (1992).

An $M_{\text {tc }}$ value of 1.35 was used as an input to the CPTu-screening techniques, based on the average from laboratory testing. Although the methods suggest the use of 1.2 at a screening level, in tailings it is common to assume a higher value, owing to increased angularity of tailings and resulting higher values for $M_{\mathrm{tc}}$ (e.g. Reid 2015a). Regardless, $M_{\mathrm{tc}}$ has a very small effect on inferred $\Psi$ using these screening methods, and the value selected does not affect the conclusions outlined here.

The mean effective stress used to plot the in situ results was based on the vertical effective stress at the centre of each tube sample depth range, and an assumed $K_{0}$ of 0.7 .

It is noted that the two methods used to estimate in situ state presented on Figure 5 were carried out using quite different measures - one being in situ density from tube samples GWC compared to the laboratory-inferred CSL, the other completely distinct CPTu-screening methods. However, for both methods, good agreement is seen, with all the in situ densities consistent with the range of $\Psi$ inferred from the CPTu. It is noted that the range of $\Psi$ inferred from the CPTu are generally quite large, presumably a result of layering/variation within the samples, the detail of which is "smeared" when combining the tube sample into one sample for GWC measurement. Indeed, gradation and TDS within this TSF have been seen to vary significantly across thicknesses of as little as $100 \mathrm{~mm}$ (Reid 2015b). Notwithstanding this layering, the agreement of the two methods outlined in Figure 5 suggests that the CSL determined using reconstituted MT samples, with the 
measures used to include similar concentration of salt in the samples, is relevant to the in situ material.

Having measured the CSL in the laboratory, it is possible to further refine the $\Psi$ estimate from the CPTu by directly using a logarithmic-fit CSL slope $\left(\lambda_{10}\right)$ for the CSL, rather than relying on screening-level estimates of $\lambda_{10}$ that are intrinsic to the methods of Plewes et al, (1992) and Been and Jefferies (1992). However, comparison of the inferred CSL slope to the predictions from the above authors suggests reasonable agreement between the laboratory-measured CSL slope and the range of slopes suggested by the empirical correlations. Emphasis is placed on the fact that the empirical correlations provide a range of slopes, as the relevant inputs (Friction Ratio and Soil Behaviour Type Index) vary across the $0.5 \mathrm{~m}$ sampling interval, again presumably as a result of layering.

Another interesting observation relates to the comparison of in situ densities to those achievable from the moist tamping technique, which is generally the laboratory reconstitution technique that achieves the loosest density. It is emphasised that the sample preparation used in this study targeted the loosest densities that could be achieved, to assist in identification of the CSL - i.e., by minimising shear localisation within the samples, as is more likely for dense samples (e.g. Desrues et al. 1996). For Samples A and B, which are from portions of the tailings that were deposited subaerially, it was possible to prepare high-salt specimens as loose as that observed in situ. However, the in situ state of Sample C was considerably looser than could be achieved in the laboratory. It is noteworthy that the Sample C location and depth was near a historic decant pond, and hence the material was likely to have been deposited subaqueously, i.e. by pluviating through saline decant water (which is of course denser than non-saline water). The sample was also likely exposed to less 
subsequent drying than the other samples, which is consistent with the lower TDS for this sample. Difficulties preparing silty tailings to densities as loose as those observed in situ have been previously observed (Cunning and Jefferies 2004; Shuttle and Cunning 2007; Reid et al. 2018b), and the different states generally resulting from subaerial and subaqueous deposition have previously been noted (Reid and Jefferies 2017). The reasons for this observed behaviour are not fully clear - although the effects of the pluviation of soils through "dirty" water has been suggested as a potential contributing factor (Vaughn 1997).

\section{Additional low-salt tests and flushing test}

The high-salt CSLs outlined in Figure 4 are again reproduced in Figure 8 for Samples A and B, again without the high-salt test paths for clarity. Presented against these CSLs are the low-salt tests, and the single test on Sample A where the sample was flushed with deionised water.

The consolidated states of the low-salt specimens were all considerably denser than the high-salt specimens. This was despite the same preparation method being employed, with the goal of preparing the specimens as loose as practicable. The consolidated state for the samples without salt, being below the CSL that was derived for high-salt samples, would suggest a dilative response if CSL was independent of TDS. Instead, a predominately contractive response is observed (refer Figure 8). While one of the low-salt tests did not achieve what appeared to be critical state conditions, it is suggested that given the distance from the high-salt CSL, and the generally contractive behaviour of the low-salt samples from these states, the CSL is dependent on TDS. This result is consistent with some preliminary results of the effect of salts on the CSL of clays (Wang and Siu 2006). This 
behaviour is also generally consistent with the changes seen in sensitive clays when tested with and without salt (Bjerrum 1954; Lessard and Mitchell 1985).

The differences in the CSL for low-salt samples appeared to be greater for Sample A, which is noteworthy as the in situ and high-salt tested TDS of Sample A was the highest of any of the samples in this study. This may further suggest a dependence of CSL on TDS. However, the quantity of tests possible in this study, which relied upon material recovered from depth in limited quantities were too small to enable any definitive conclusions to be drawn.

The behaviour of the sample flushed with deionised water is outlined in Figure 8a. The initial consolidated density is consistent with other high-salt samples. The flushing is seen to result in some decrease in void ratio. However, it is unclear what proportion of this reduction may be creep (owing to the three week flushing period), and what proportion is a result of the reduction in salinity. In any event, the shear behaviour of the sample exhibits initially contractive response followed by a phase transformation to dilation - importantly, then tending towards the high-salt CSL in the process. Indeed, the manner of initial contraction followed by dilation is quite typical of a sample with the $\Psi_{0}$ relevant to the flushing test - that is if $\Psi_{0}$ for that test is calculated based on the high-salt CSL. Therefore, this result would appear to suggest that reduction of salinity, at least of the magnitude achieved herein and in the time available, did not produce a metastable fabric such as those seen in sensitive clays that undergo a conceptually similar history of pore fluid variation.

The reasons for this lack of increased sensitivity following reduction in salinity are unknown. Previous laboratory testing programs that have successfully developed sensitivity through salinity reduction (Bjerrum and Rosenqvist 1956) were carried out 
over a period of 18 months. It may, therefore, require significant time for the reduced salinity to interact with soil particles. Further, although the overall salinity of the specimen was reduced to about $3 \mathrm{~g} / \mathrm{L}$, it is conceivable that much of the remaining salt was closely bound to particle faces and edges - perhaps the process of removal of salts from these areas requires more time than the three weeks of flushing used in this study. Alternatively, as discussed subsequently, it has been clearly indicated that reduction in pore fluid salinity is not in itself sufficient to develop a highly sensitivity material (e.g. Mitchell and Soga 2005). Whatever the reasons for the lack of increase in sensitivity in the one flushing test carried out in this study, clearly additional work is necessary to identify tailings for which such behaviour may occur.

The inability to appreciably change the tailings behaviour with flushing may indicate that flushing of some soils to reduce the potential effects of a given pore fluid chemistry may not be successful. This may be an important issue for consideration with respect to the work of Chang et al. (2011), where attempts were made to flush flocculated samples prepared from a slurry. Therefore, it is conceivable that some of the differences seen by Chang et al. between slurry prepared specimens (with flocculant) and other reconstitution techniques (that did not involve use of a flocculant) may be a result of the presence of the flocculants themselves, which are known to affect the CSL (Reid and Fourie 2016).

\section{PORE FLUID CHEMISTY}

Mitchell and Soga (2005) and Helle et al. (2017) summarise and further discuss the development of sensitivity in clays, particularly the observation that reduction in salt concentration is generally insufficient, in itself, to generate highly sensitive soils. Mitchell and Soga, based on data from Penner (1965) indicate that the percent 
monovalent cations in the pore fluid provides a useful check on potential for development of "very high sensitivities", based on the following ratio:

$$
\frac{\mathrm{Na}^{+}+\mathrm{K}^{+}}{\mathrm{Na}^{+}+\mathrm{K}^{+}+\mathrm{Ca}^{2+}+\mathrm{Mg}^{2+}}
$$

\section{(1)}

With all values in meq/L. A resulting ratio of greater than 0.75 is required for very high sensitives to develop. Alternatively, Helle et al. (2017) emphasise the greater importance of $\mathrm{K}+$ to $\mathrm{Na}+$, and propose an alternative ratio to assess potentially high sensitivity (defined as remoulded shear strength $<1 \mathrm{kPa}$ ), as follows:

$$
\frac{\mathrm{K}^{+}+\mathrm{Mg}^{2+}+\mathrm{Ca}^{2+}}{\mathrm{Na}^{+}+\mathrm{K}^{+}+\mathrm{Ca}^{2+}+\mathrm{Mg}^{2+}}
$$

Where high sensitivities are expected when the result falls below 0.20.

The results of both ratios for the tailings pore fluid obtained from the site decant pond, and after the addition of synthetic pore fluid consisting only of sodium chloride salt as the back pressure fluid are outlined in Table 5. It is seen that addition of synthetic pore fluid results in only slight variations to these ratios, in both cases indicating a slightly higher potential for development of a high sensitivity as a result of the pore fluid variation.

Regardless of which ratio is used for comparison, the reduction in TDS of the tailings tested in this study, combined with the pore fluid constituents, would indicate the potential for a significant increase in sensitivity. However, the results of the single flushing test available are inconsistent with that indication. Instead, the flushed 
sample tends towards the high-salt CSL, indicating no significant change to mechanical behaviour (aside from some potential creep during flushing). It may be that the tailings tested in this study differ from the soils used to generate various screening tools for increased sensitivity, given that previous studies were primarily focussed towards marine clays.

\section{POTENTIAL IMPLICATIONS AND FUTURE QUESTIONS}

With respect specifically to Western Australian tailings management practice, it is clear that considerable care is necessary in managing dissolved solids present in tailings pore fluids during geotechnical characterisation involving reconstituted specimens. This level of care is not currently being applied in most of the industry. This would be particularly important if comparing the results of reconstituted tests to measured in situ densities, as was done with the tube samples in this study. Excluding pore fluid considerations in such a comparison might result in significant error in inferred $\Psi$.

It remains unclear what would occur to the mechanical behaviour of a tailings of this type, deposited and consolidated in a high salinity environment, which may then over long periods experience a reduction in salt concentration through environmental factors (i.e. seepage, driven by precipitation). While the single flushing test carried out did not show an increased sensitivity, with the material tending towards the same CSL as the high-salt specimens, further examination of this issue is crucial, given the potential risks involved for long term tailings stability.

More generally, it is unclear what quantity of dissolved solids would result in significant mechanical effects, and for what type or range of tailings materials such effects could manifest. As noted previously, many tailings liquours have appreciable 
quantities of dissolved solids (Poulos et al. 1985; Fahey and Newson 1997; Fujiyasu and Fahey 2000; Al-Tarhouni et al. 2011; Mundle et al. 2012; Gorakhki and Bareither 2016). The available data from clays indicate that variation of salt content at relatively low TDS ranges ( $~ 5$ to $20 \mathrm{~g} / \mathrm{L}$ ) can significantly affect index properties and mechanical behaviour (e.g. Bjerrum 1954). This range of TDS is common in tailings pore fluids. This may therefore be important to consider for studies that compare the behaviour of in situ and reconstituted samples of tailings, and for the preparation of reconstituted samples more generally.

It is also unclear at present if there is a limiting upper TDS value, above which further changes to pore fluid chemistry have minimal subsequent effects on mechanical behaviour or index properties. This appears to be suggested by the trends typically seen of Atterberg Limits with TDS (Bjerrum 1954; Helle et al. 2019). This potential behaviour may have also played a role in some of the results outline herein, as for each sample tested with high-salt a consistent CSL was inferred for all tests, despite there being some variation in TDS in each triaxial test carried out.

\section{LIMITATIONS}

While the results presented here, in our view, clearly show the importance of consideration of pore fluid chemistry in assessing the CSL of tailings, there are a number of limitations to this initial study. Firstly, as this was, to our knowledge, the first attempt to reproduce in situ hypersaline conditions in reconstituted triaxial specimens, some development and iteration was required in methods. Sample A and B specimens exceeded the in situ salinity, while Sample C specimens, which incorporated "lessons learned", were a closer match to in situ values. Similarly, the use of synthetic pore fluid must also be viewed as a limitation - particularly given 
that pore fluid constituents, not just TDS, may control an increase in sensitivity during flushing.

Secondly, and of greatest importance, was reliance on material obtained from piston samples. Although this enabled useful comparisons to CPTu techniques to estimate $\Psi$, the downside was the limited quantity of sample obtained. As such, it was not possible to carry out a comprehensive set of tests with a variety of salt concentrations, different preparation methods, such as slurry deposition, and to investigate at what range of plasticity (for example) such effects would manifest. Limited assessment of the effects of removal of salts by flushing, after consolidation, was possible. Clearly, further study of the effects of dissolved solids on tailings behaviour are warranted, particularly given the frequent contribution of contractive undrained shearing to slope instability of these structures (for example, Davies et al. 2002), the increasing application of critical state techniques in their analysis (Morgenstern et al. 2016; Shuttle and Jefferies 2016), and the apparent confirmation from this study that the hypothesised importance of pore fluid chemistry (Jamiolkowsi 2014) on the relevance of reconstituted samples appears valid.

Finally, the use of moist tamping requires acknowledgement as a limitation - given that this sample preparation method has received considerable criticism, generally related to (a) non-uniformity of initial specimen void ratio (Vaid et al. 1999; Daliri et al. 2015), and (b) producing fabric and/or densities inconsistent with intact specimen behaviour (Vaid and Sivathayalan 2001; Daliri et al. 2015) - despite the fact that, for predominately silt tailings, no sample preparation method has yet been shown to clearly produce the same shearing response compared to intact specimens of the same material (Høeg et al. 2000; Chang et al. 2011). Alternatively, it also suggested that the observation in this paper of in situ states looser than can be achieved with 
any sample preparation method, including moist tamping, for Sample C - a similar issue demonstrated in other studies (Fourie and Papageorgiou 2001; Shuttle and Cunning 2007; Reid et al. 2018b) - is an additional factor that should be considered in the context of the suitability of different preparation techniques to simulate in situ behaviour.

Regardless of ongoing debates about sample preparation techniques, in the context of this paper, it would seem reasonable that methods involving the pouring of a slurry, drying, then rewetting (Al-Tarhouni et al. 2011; Daliri et al. 2014) would be most suitable - given the clear indication of desiccation of the samples in terms of TDS and inferred OCR (refer Table 2 and 3). However, it is noted that early attempts in this study to prepare samples from non-segregating slurry (a requirement for laboratory element tests) resulted in denser states than measured in situ by CPTu-inferred methods and the GWC of tubes. Further, in our experience, the drying back of hypersaline slurries to produce uniform samples for element testing is impractical - when drying back such material, significant salt accumulation and crusting occurs (e.g. Mundle et al. 2012). Salt accumulation occurs to the point where salt crystals "spread" upwards, and in some cases outside of the drying container and onto the laboratory bench. It is unclear how a uniform specimen for subsequent element testing could be produced given such behaviour. For these reasons, moist tamping was used in this study - primarily for the purposes of measuring the CSL of tailings - i.e. a large-strain condition, where the initial density variations through the sample are likely to have become negligible (Thomson and Wong 2008). However, it is acknowledged that given the ongoing debates regarding the preparation methods for reconstituted silt tailings, further study of the effects of salinity on tailings should include additional sample preparation methods. 


\section{CONCLUSIONS}

Samples were recovered from adjacent to CPTu probes within a gold TSF with hypersaline slurry fluid in Western Australia. A series of reconstituted triaxial tests were carried out on the samples to estimate the CSL, with measures taken to produce similar salt concentrations in the laboratory to those measured in situ. Comparison of laboratory-inferred CSLs to measured in situ density from piston tube GWCs compared favourably to the $\Psi$ inferred from CPTu methods across the same depth range. Additional samples prepared on washed material (i.e. low-salt) resulted in generally higher densities, tending towards a different CSL to the samples with high-salt. The differences seen between samples with high and low TDS were consistent with similar test programs on clays. The results suggest significant additional care is required in Western Australian tailings practice when testing reconstituted samples with hypersaline pore fluid. Further, the potential relevance of the results of this work on fabric studies comparing intact and reconstituted samples was highlighted

\section{ACKNOWLEDGEMENT}

The first author thanks the anonymous client for the geotechnical investigation program who supported the publication of this study.

\section{REFERENCES}

Al-Tarhouni, M., Simms, P., and Sivathayalan, S. 2011. Cyclic behaviour of reconstituted and desiccated-rewet thickened gold tailings in simple shear. Canadian Geotechnical Journal, 48(7): 1044-1060. doi:10.1139/t11-022.

Baziar, M.H., and Dobry, R. 1995. Residual Strength and Large-Deformation Potential of Loose Silty Sands. Journal of Geotechnical Engineering, 121(12): 896-906. doi:10.1061/(ASCE)07339410(1995)121:12(896). 
Been, K., and Jefferies, M.G. 1992. Towards systematic CPT interpretation. In Predictive soil mechanics: The Wroth Memorial Symposium, Oxford, U.K. pp. 121-134.

Bjerrum, L. 1954. Geotechnical Properties of Norwegian Marine Clays. Géotechnique, 4(2): 49-69. doi:10.1680/geot.1954.4.2.49.

Bjerrum, L., and Rosenqvist, I.T. 1956. Some Experiments With Artificially Sedimented Clays. Géotechnique, 6(3): 124-136. doi:10.1680/geot.1956.6.3.124.

Chang, N. 2009. The effect of fabric ont he behaviour of gold tailings. Faculty of Engineering, Built Environment, and Information Technology, University of Pretoria, Pretoria.

Chang, N., Heymann, G., and Clayton, C. 2011. The effect of fabric on the behaviour of gold tailings. Géotechnique, 61(3): 187-197. doi:10.1680/geot.9.P.066.

Cunning, J., and Jefferies, M. 2004. On applying liquefaction case history experience to tailings. In Proceedings of the CDA 2004 Annual Conference, Ottawa, Ontario.

Daliri, F., Simms, P., and Sivathayalan, S. 2015. Discussion of "Stiffness and Strength Governing the Static Liquefaction of Tailings" by F. Schnaid, J. Bedin, A. J. P. Viana da Fonseca, and L. de Moura Costa Filho. Journal of Geotechnical and Geoenvironmental Engineering, 141(9): 07015023. doi:10.1061/(ASCE)GT.1943-5606.0001328.

Daliri, F., Kim, H., Simms, P., and Sivathayalan, S. 2014. Impact of Desiccation on Monotonic and Cyclic Shear Strength of Thickened Gold Tailings. Journal of Geotechnical and Geoenvironmental Engineering, 140(9): 04014048. doi:10.1061/(ASCE)GT.19435606.0001147.

Davies, M.P., McRoberts, E.C., and Martin, T.E. 2002. Static liquefaction of tailings - fundamentals and case histories. In Tailings Dam 2002: Proceedings of the Joint ASDSO/USSD Specialty Conference, Las Vegas, Nevade. pp. 233-255.

DeJong, J.T., and Randolph, M. 2012. Influence of Partial Consolidation during Cone Penetration on Estimated Soil Behavior Type and Pore Pressure Dissipation Measurements. Journal of Geotechnical and Geoenvironmental Engineering, 138(7): 777-788. doi:doi:10.1061/(ASCE)GT.1943-5606.0000646.

Desrues, J., Chambon, R., Mokni, M., and Mazerolle, F. 1996. Void ratio evolution inside shear bands in triaxial sand specimens studied by computed tomography. Géotechnique, 46(3): 529-546. doi:10.1680/geot.1996.46.3.529. 
Fahey, M., and Newson, T. 1997. Aspect of the geotechnics of mining wastes and tailings dams. In Environmental geotechnics : proceedings of the 1st Australia-New Zealand Conference on Environmental Geotechnics-GeoEnvironment 97. Edited by J.K. Kodikara and A. Bouazza and R. Parker. A.A. Balkema, Melbourne, Victoria, Australia. pp. 115-134.

Fourie, A.B., and Papageorgiou, G. 2001. Defining an appropriate steady state line for Merriespruit gold tailings. Canadian Geotechnical Journal, 38(4): 695-706. doi:10.1139/t00-111.

Fujiyasu, Y., and Fahey, M. 2000. Experimental Study of Evaporation from Saline Tailings. Journal of Geotechnical and Geoenvironmental Engineering, 126(1): 18-27. doi:10.1061/(ASCE)10900241(2000)126:1(18).

Ghafghazi, M., and Shuttle, D. 2008. Interpretation of sand state from cone penetration resistance. Géotechnique, 58(8): 623-634. doi:10.1680/geot.2008.58.8.623.

Gorakhki, M., and Bareither, C. 2016. Effects of Salinity on the Geotechnical Characterization of FineGrained Soils and Mine Tailings. Geotechnical Testing Journal, 39(1): 45-58.

Helle, T.E., Aagaard, P., and Nordal, S. 2017. In Situ Improvement of Highly Sensitive Clays by Potassium Chloride Migration. Journal of Geotechnical and Geoenvironmental Engineering, 143(10): 04017074. doi:10.1061/(ASCE)GT.1943-5606.0001774.

Helle, T.E., Nordal, S., and Aagaard, P. 2018. Improved geotechnical properties in salt-treated highly sensitive landslide-prone clays. Proceedings of the Institution of Civil Engineers Geotechnical Engineering, 171(3): 232-242. doi:10.1680/jgeen.17.00071.

Helle, T.E., Aagaard, P., and Nordal, S. 2019. Closure to "In Situ Improvement of Highly Sensitive Clays by Potassium Chloride Migration"; by Tonje Eide Helle, Per Aagaard, and Steinar Nordal. Journal of Geotechnical and Geoenvironmental Engineering, 145(4): 07019004. doi:doi:10.1061/(ASCE)GT.1943-5606.0002030.

Høeg, K., Dyvik, R., and Sandbækken, G. 2000. Strength of Undisturbed versus Reconstituted Silt and Silty Sand Specimens. Journal of Geotechnical and Geoenvironmental Engineering, 126(7): 606-617. doi:10.1061/(ASCE)1090-0241(2000)126:7(606).

Imai, G., Tsuruya, K., and Yano, K. 1979. A treatment of salinity in water content determination of very soft clays. Soils and Foundations, 19(3): 84-89. doi:10.3208/sandf1972.19.3_84. 
Jamiolkowsi, M. 2014. Sixth J.K. Mitchell Lecture - Role of in-situ testing in geotechnical characterization of copper tailings (Presentation). In 3rd International Symposium on Cone Penetration Testing, Las Vegas, Nevada.

Jefferies, M.G., and Been, K. 2015. Soil Liquefaction: A Critical State Approach. 2nd ed. CRC Press, Boca Raton, FL.

Kay, S., Goedemoed, S., and Vermeijden, C. 2005. Influence of salinity on soil properties. In Frontiers in Offshore Geotechnics : ISFOG 2005 : proceedings of the first International Symposium on Frontiers in Offshore Geotechnics. Edited by S. Gourvenec and M. Cassidy. Taylor and Francis, Perth, Western Australia, Australia. pp. 1087-1093.

Ladd, R. 1978. Preparing Test Specimens Using Undercompaction. Geotechnical Testing Journal, 1(1): 16-23.

Lessard, G., and Mitchell, J.K. 1985. The causes and effects of aging in quick clays. Canadian Geotechnical Journal, 22(3): 335-346. doi:10.1139/t85-046.

Mayne, P.W. 2014. Generalized CPT method for evaluating yield stress in soils. In Geocharacterization for modeling and sustainability. Edited by M. Abu-Farsakh and X. Yu and L.R. Hoyos. ASCE, Atlanta, GA. pp. 1336-1346.

Mayne, P.W., Styler, M., Woeller, D.J., and Sharp, J. 2017. Identifying contractive soils by CPT material index for flow liquefaction concerns. In GeoOttawa 2017. CGS, Ottawa, ON.

Mitchell, J., and Soga, K. 2005. Fundamentals of soil behaviour, 3rd Edition. Wiley, Hoboken, N.J. Mohajeri, M., and Ghafghazi, M. 2012. Ground sampling and laboratroy testing on a low plasticity clay. In Proceedings of the 15th World Conference on Earthquake Engineering. Sociedade Portuguesa de Engenharia Sismica, Lisbon, Portugal.

Morgenstern, N.R., Vick, S.G., Viotti, C.B., and Watts, B.D. 2016. Fundão Tailings Dam Review Panel: Report in the immediate causes of the failure of the Fundão Dam.

Mundle, C., Chapman, P., Williams, D., and Fredlund, D. 2012. The impact of high density liquors on standard soil mechanics calculations. In Proceedings 16th International Conference on Tailings and Mine Waste. Information Technology, Creative Media, Keystone, Colorado. pp. $281-290$

Noorany, I. 1984. Phase Relations in Marine Soils. Journal of Geotechnical Engineering, 110(4): 539543. doi:10.1061/(ASCE)0733-9410(1984)110:4(539). 
Northcutt, S., and Wijewickreme, D. 2013. Effect of particle fabric on the coefficient of lateral earth pressure observed during one-dimensional compression of sand. Canadian Geotechnical Journal, 50(5): 457-466. doi:10.1139/cgj-2012-0162.

Penner, E. 1965. A STUDY OF SENSITIVITY IN LEDA CLAY. Canadian Journal of Earth Sciences, 2(5): 425-441. doi:10.1139/e65-037.

Pineda, J.A., Suwal, L.P., Kelly, R.B., Bates, L., and Sloan, S.W. 2016. Characterisation of Ballina clay. Géotechnique, 66(7): 556-577. doi:10.1680/jgeot.15.P.181.

Plewes, H.D., Davies, M.P., and Jefferies, M.G. 1992. CPT based screening procedure for evaluation liquefaction susceptibility. In 45th Canadian Geotechnical Conference. Canadian Geotechnical Society, Toronto, ON. pp. 41-49.

Poulos, S., Robinsky, E., and Keller, T. 1985. Liquefaction Resistance of Thickened Tailings. Journal of Geotechnical Engineering, 111(12): 1380-1394. doi:10.1061/(ASCE)07339410(1985)111:12(1380).

Pournaghiazar, M., Russell, A.R., and Khalili, N. 2013. The cone penetration test in unsaturated sands. Géotechnique, 63(14): 1209-1220. doi:10.1680/geot.12.P.083.

Reid, D. 2015a. Estimating slope of critical state line from cone penetration test — an update. Canadian Geotechnical Journal, 52(1): 46-57. doi:10.1139/cgj-2014-0068.

Reid, D. 2015b. Observations on the behaviour of a gold tailings with hypersaline pore fluid. In Tailings and Mine Waste Management for the 21st Century. Edited by F.R. Nejad. AUSIMM, Sydney, Australia. pp. 191-200.

Reid, D., and Fourie, A.B. 2016. Laboratory assessment of the effects of polymer treatment on geotechnical properties of low plasticity soil slurry. Canadian Geotechnical Journal, 53(10): 1718-1730.

Reid, D., and Jefferies, M. 2017. State parameter as a geological principle in tailings. In Proceedings of Tailings and Mine Waste 2017, Banff, AB.

Reid, D., Fourie, A.B., Castro, J., and Lupo, J. 2018a. Undrained shear strength evolution with loading on an undisturbed block smaple of desiccated gold tailins. In Tailings and Mine Waste 2018. Colorado State University, Keystone, CO.

Reid, D., Fanni, R., Koh, K., and Orea, I. 2018b. Characterisation of a subaqueously deposited silt iron ore tailings. Géotechnique Letters, 8(4): 278-283. doi:10.1680/jgele.18.00105. 
Robertson, P.K. 2016. Cone penetration test (CPT)-based soil behaviour type (SBT) classification system — an update. Canadian Geotechnical Journal, 53(12): 1910-1927. doi:10.1139/cgj2016-0044.

Schneider, J.A., and Moss, R.E.S. 2011. Linking cyclic stress and cyclic strain based methods for assessment of cyclic liquefaction triggering in sands. Géotechnique Letters, 1(2): 31-36. doi:10.1680/geolett.11.00021.

Shuttle, D., and Jefferies, M. 1998. Dimensionless and unbiased CPT interpretation in sand. International Journal for Numerical and Analytical Methods in Geomechanics, 22(5): 351-391. doi:10.1002/(SICI)1096-9853(199805)22:5<351::AID-NAG921>3.0.CO;2-8.

Shuttle, D., and Jefferies, M. 2016. Determining silt state from CPTu. Geotechnical Research, 3(3): 90-118. doi:10.1680/jgere.16.00008.

Shuttle, D.A. 2006. Can the effect of sand fabric on plastic hardening be determined using a selfbored pressuremeter? Canadian Geotechnical Journal, 43(7): 659-673. doi:10.1139/t06-033.

Shuttle, D.A., and Cunning, J. 2007. Liquefaction potential of silts from CPTu. Canadian Geotechnical Journal, 44(1): 1-19. doi:10.1139/t06-086.

Sladen, J.A., and Handford, G. 1987. A potential systematic error in laboratory testing of very loose sands. Canadian Geotechnical Journal, 24(3): 462-466. doi:10.1139/t87-058.

Stiller, M., Yechieli, Y., and Gavrieli, I. 2007. The rate of dissolution of halite in diluted Dead Sea brines. Geological Survey of Israel, The Ministry of National Infrastructures, Jerusalem, Israel.

Thomson, P.R., and Wong, R.C.K. 2008. Specimen nonuniformities in water-pluviated and moisttamped sands under undrained triaxial compression and extension. Canadian Geotechnical Journal, 45(7): 939-956. doi:10.1139/T08-023.

Vaid, Y., Sivathayalan, S., and Stedman, D. 1999. Influence of Specimen-Reconstituting Method on the Undrained Response of Sand.

Vaid, Y.P., and Sivathayalan, S. 2001. Discussion of "Strength of Undisturbed versus Reconstituted Silt and Silty Sand Specimens" by K. Høeg, R. Dyvik, and G. Sandbækken. Journal of Geotechnical and Geoenvironmental Engineering, 127(11): 991-994. doi:10.1061/(ASCE)1090-0241(2001)127:11(991). 
Vaughn, P.R. 1997. Panel dicussion: Sedimentation of tailings. In Proceedings of the 14th International Conference on Soil Mechanics and Foundation Engineering. A.A. Balkema, Hamburg, Germany. pp. 2561-2562.

Wang, Y.H., and Siu, W.K. 2006. Structure characteristics and mechanical properties of kaolinite soils. II. Effects of structure on mechanical properties. Canadian Geotechnical Journal, 43(6): 601-617. doi:10.1139/t06-027.

Xu, L., and Coop, M.R. 2017. The mechanics of a saturated silty loess with a transitional mode. Géotechnique, 67(7): 581-596. doi:10.1680/jgeot.16.P.128.

Yang, H., and Russell, A.R. 2015. Cone penetration tests in unsaturated silty sands. Canadian Geotechnical Journal, 53(3): 431-444. doi:10.1139/cgj-2015-0142.

Youd, T.L., and Craven, T.N. 1975. Lateral stress in sands during cyclic loading. Journal of Geotechnical Engineering Division, 1975(2): 217-221.

Yukselen-Aksoy, Y., Kaya, A., and Ören, A.H. 2008. Seawater effect on consistency limits and compressibility characteristics of clays. Engineering Geology, 102(1): 54-61. doi:https://doi.org/10.1016/j.enggeo.2008.07.005.

Zhu, F., and Clark, J.I. 1994. The effect of dynamic loading on lateral stress in sand. Canadian Geotechnical Journal, 31(2): 308-311. doi:10.1139/t94-036. 


\section{Figure caption list}

Figure 1: CPTu results: (a) CPTu 1; (b) CPTu 2

Figure 2: XRD results: (a) Sample A; (b) Sample B; (c) Sample C

Figure 3: TDS - Specific Gravity relationship for $\mathrm{NaCl}$ in water, and measurements taken in this study

Figure 4: Sample A HS triaxial test results: (a) deviator stress vs. strain; (b) deviator stress vs. mean effective stress

Figure 5: Sample B HS triaxial test results: (a) deviator stress vs. strain; (b) deviator stress vs. mean effective stress

Figure 6: Sample C HS triaxial test results: (a) deviator stress vs. strain, (b) deviator stress vs. mean effective stress

Figure 7: High salt sample state plots: (a) Sample A; (b) Sample B; (c) Sample C

Figure 8: In situ state estimates compared to HS CSL: (a) Sample A; (b) Sample B; (c) Sample C

Figure 9: HS CSL compared to low salt tests and flushing test: (a) Sample A; (b) Sample B 
(a) CPTu 1
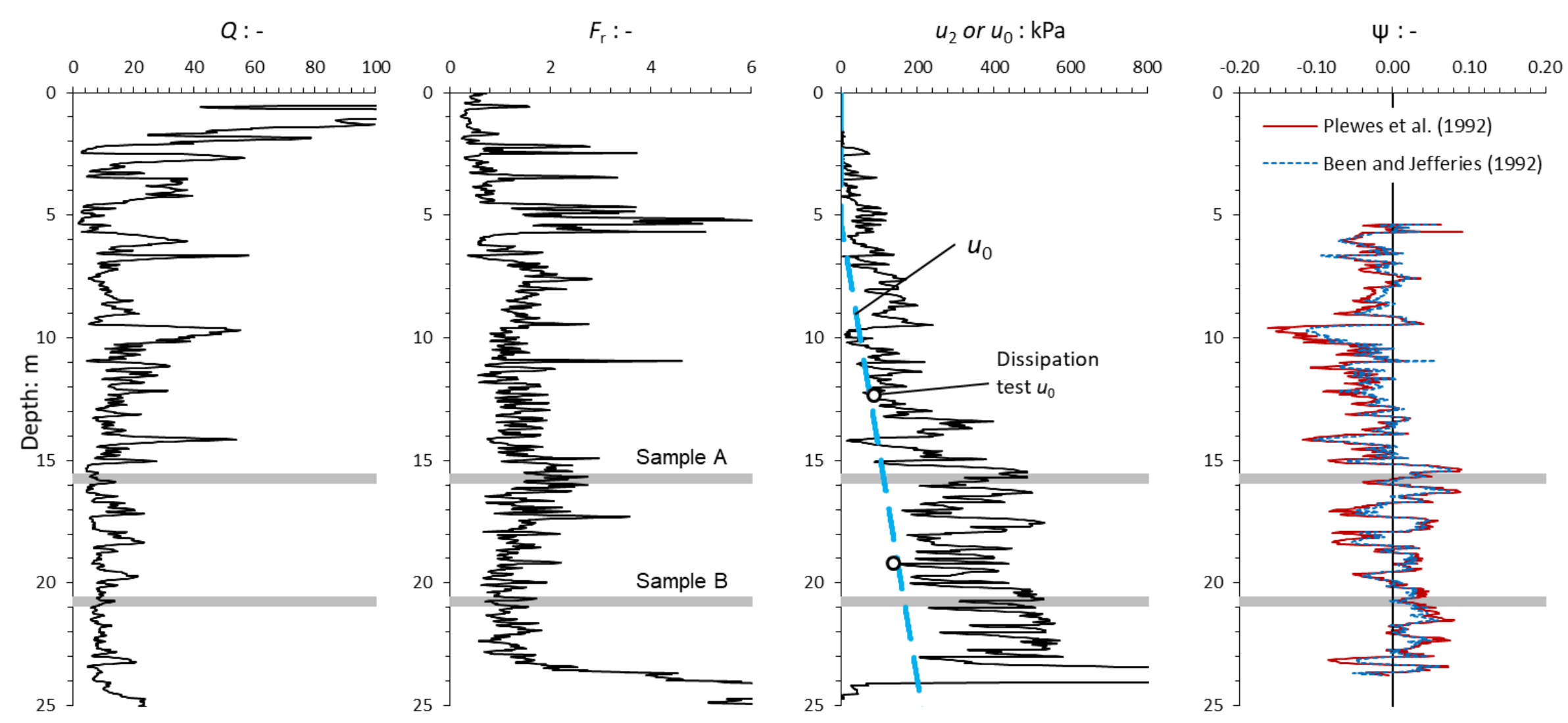
(b) CPTu 2

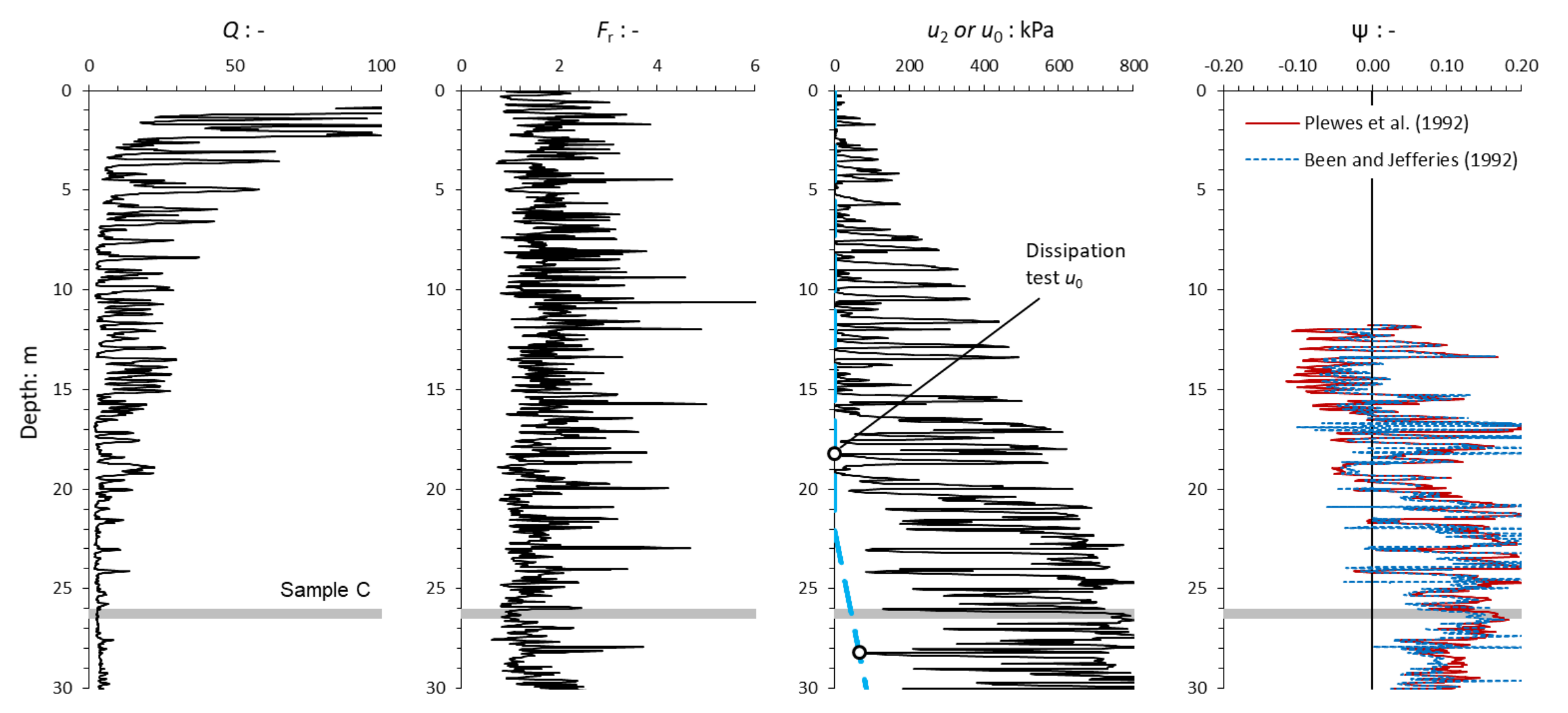

Figure 1: CPTu results: (a) CPTu 1; (b) CPTu 2 

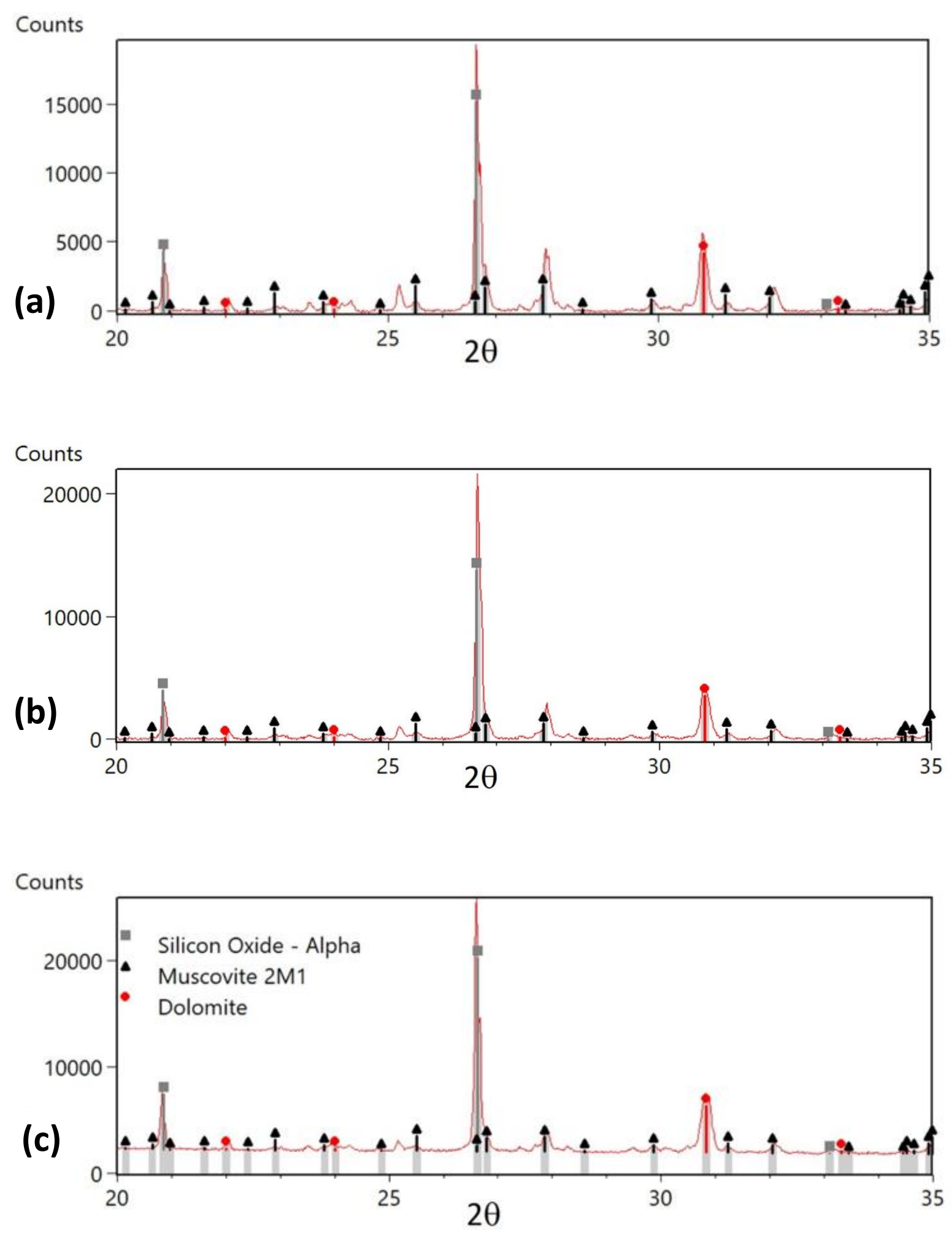

Figure 2: XRD results: (a) Sample A; (b) Sample B; (c) Sample C 


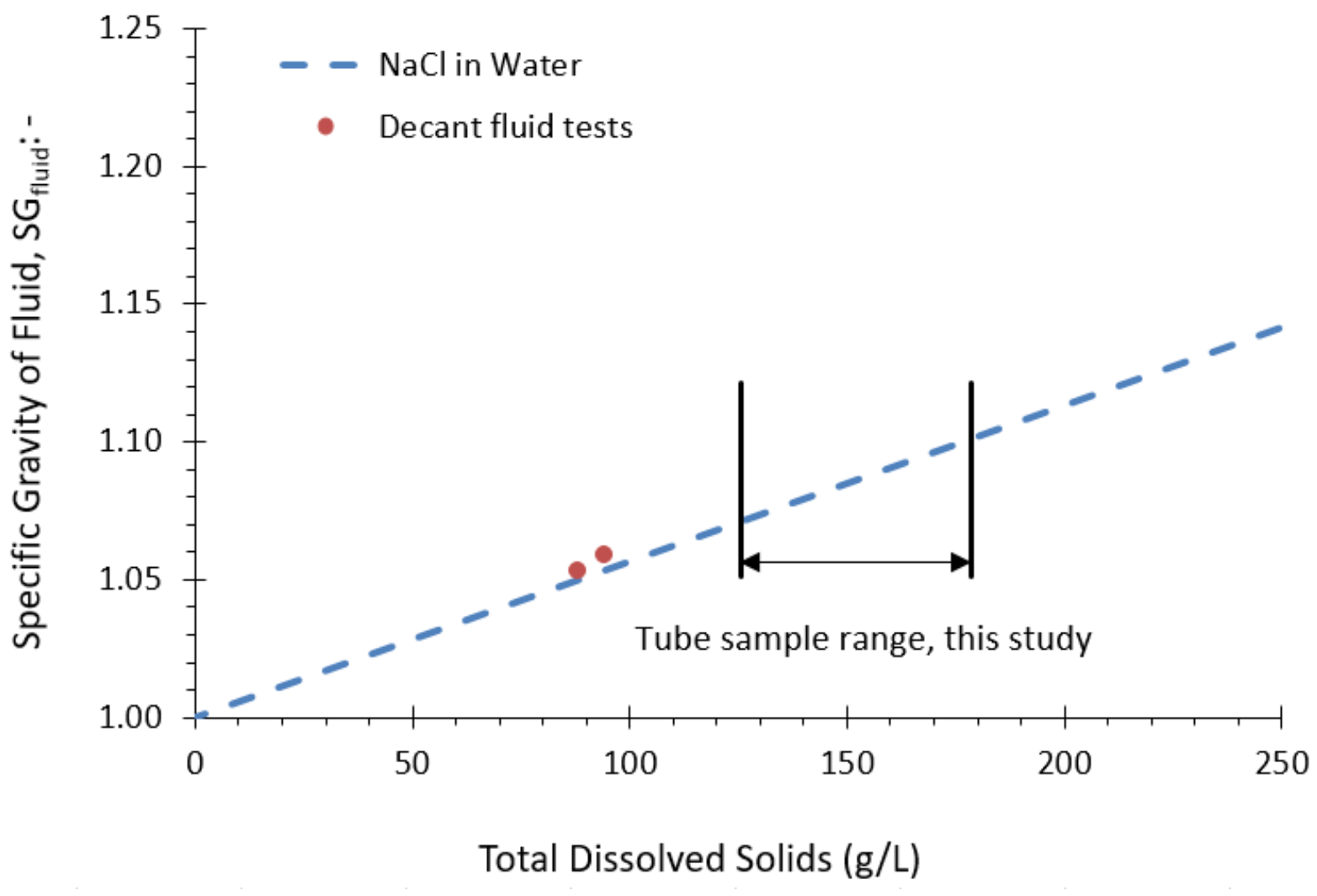

Figure 3: TDS - Specific Gravity relationship for $\mathrm{NaCl}$ in water, and measurements taken in this study 
(a)

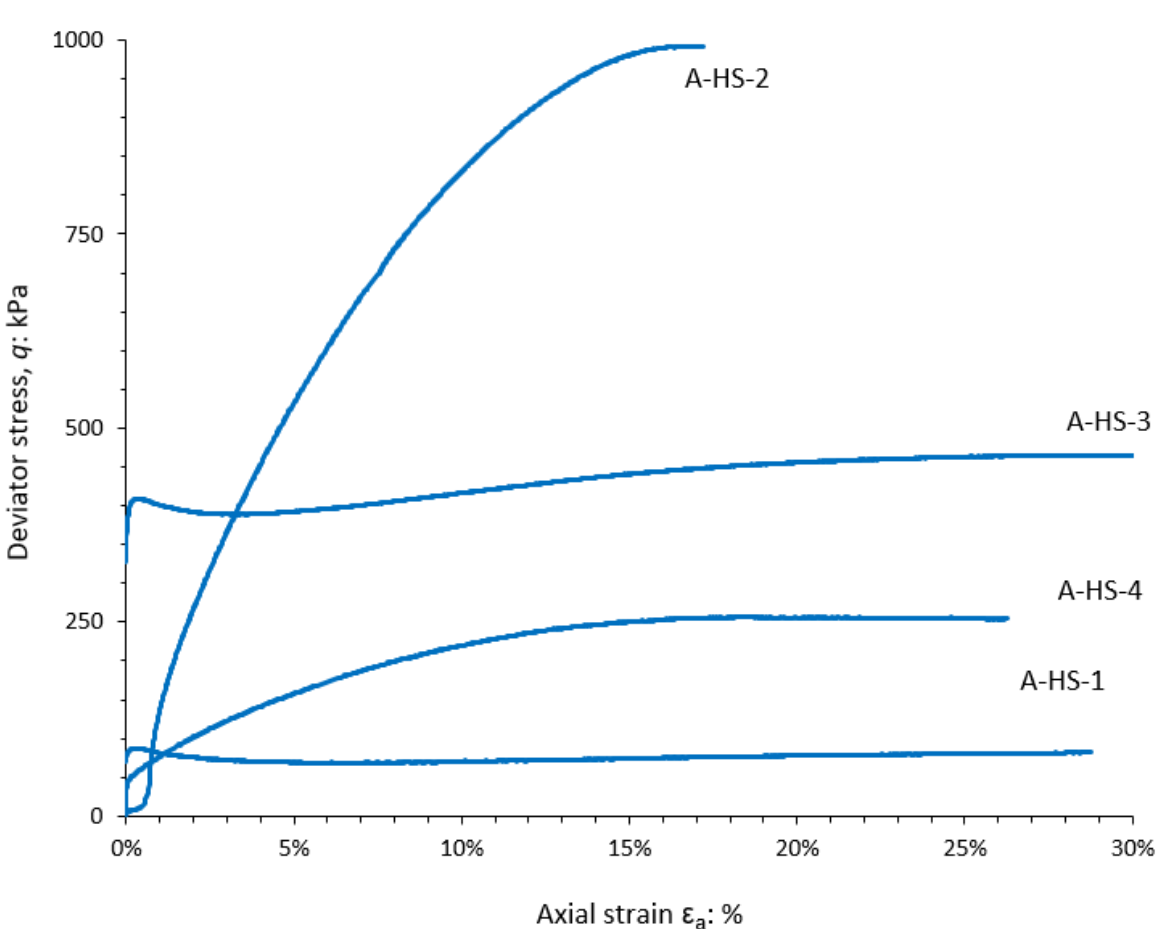

(b)

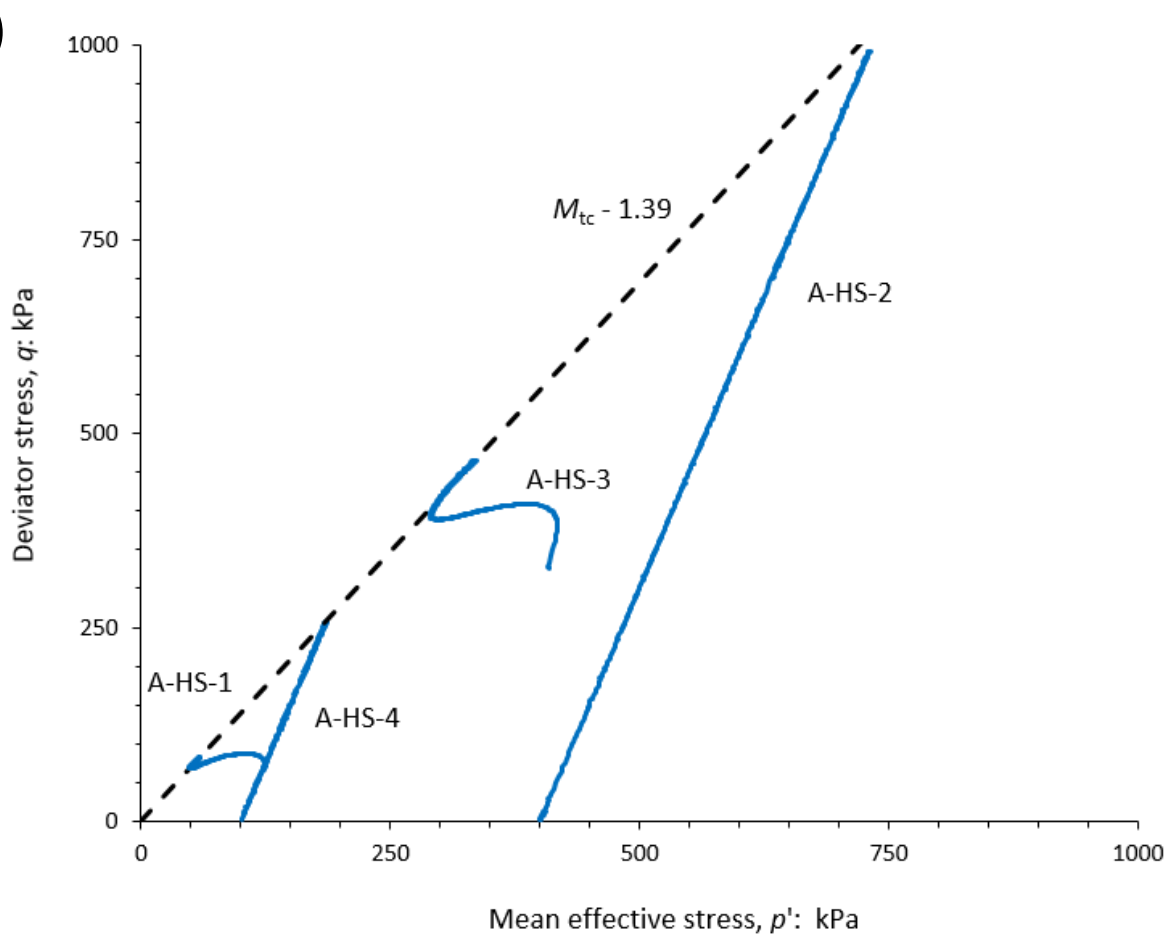

Figure 4: Sample A HS triaxial test results: (a) deviator stress vs. strain; (b) deviator stress vs. mean effective stress 
(a)

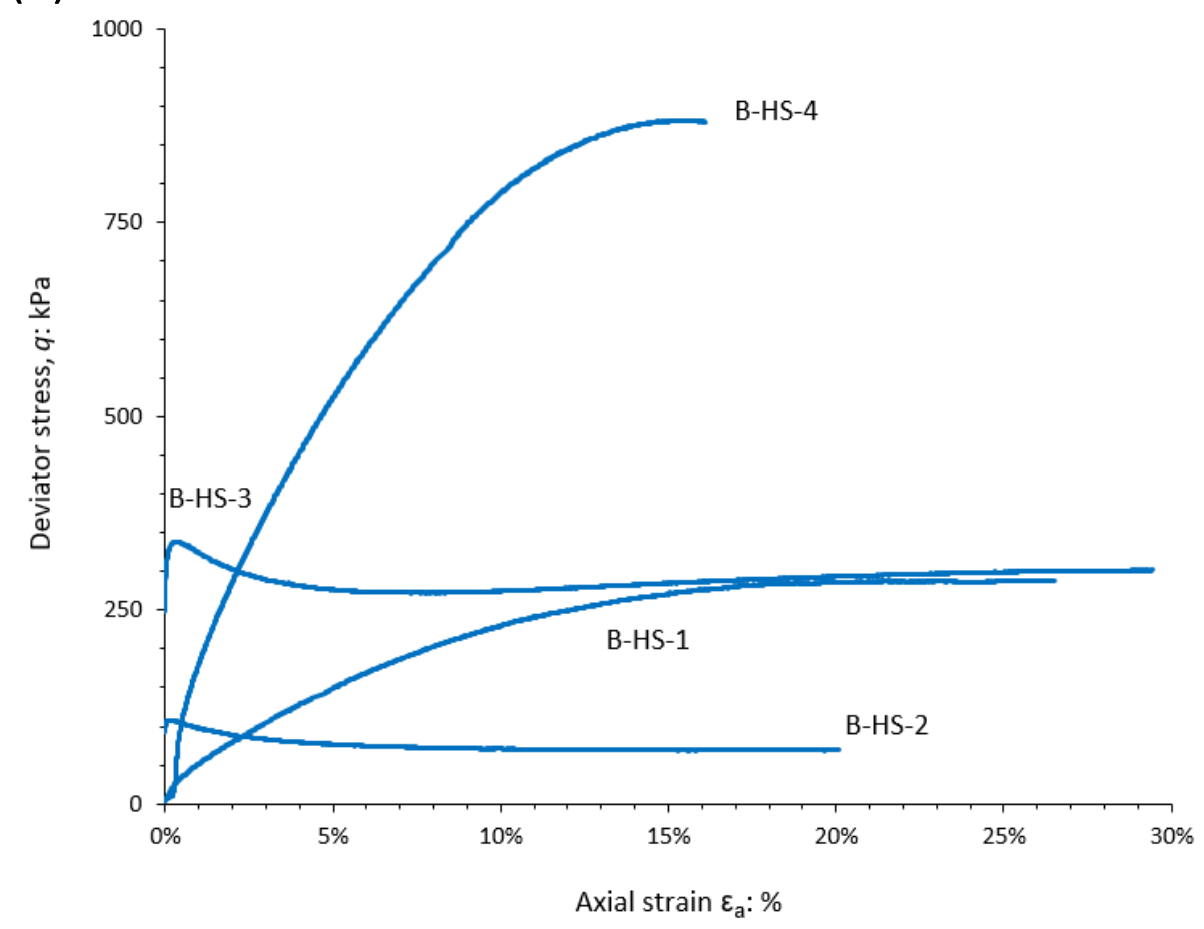

(b)

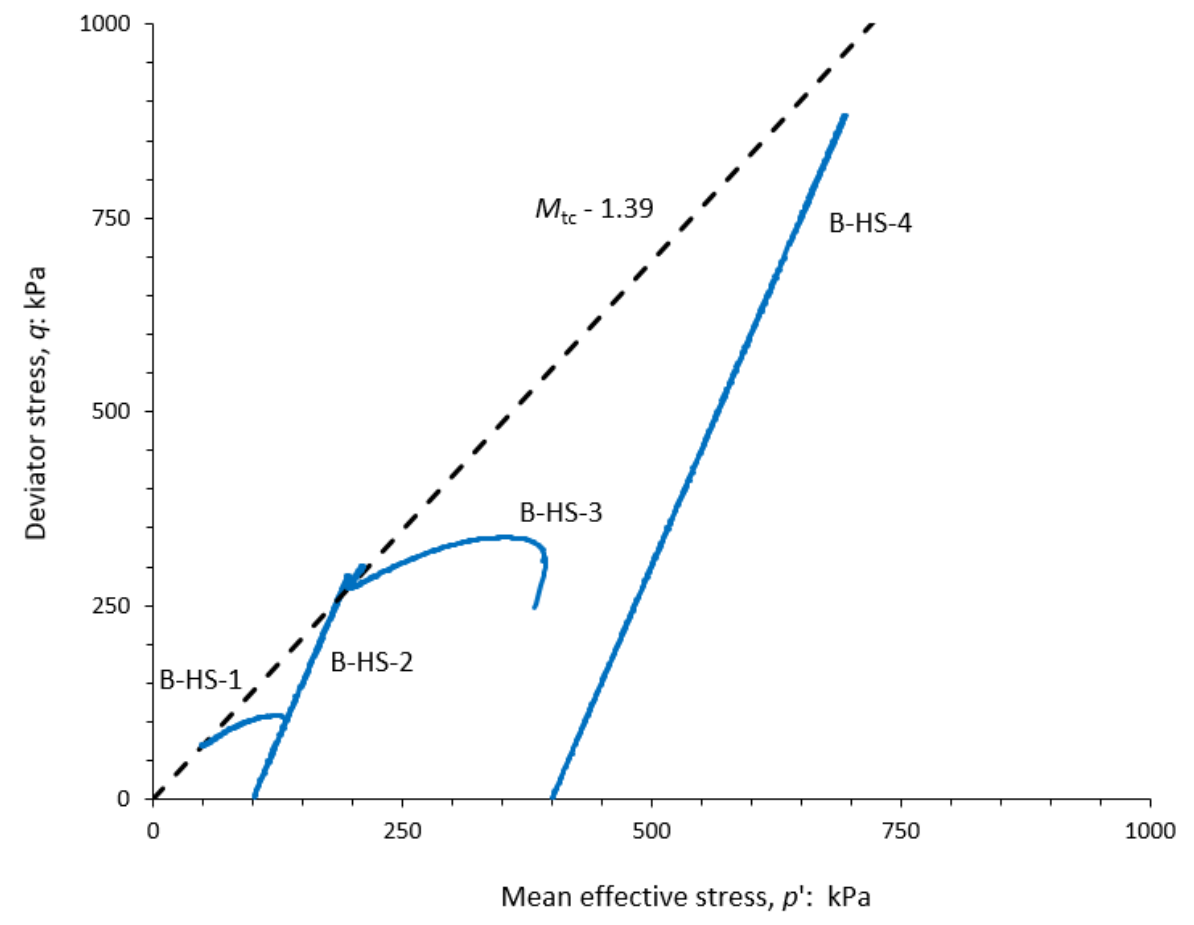

Figure 5: Sample B HS triaxial test results: (a) deviator stress vs. strain; (b) deviator stress vs. mean effective stress 
(a)

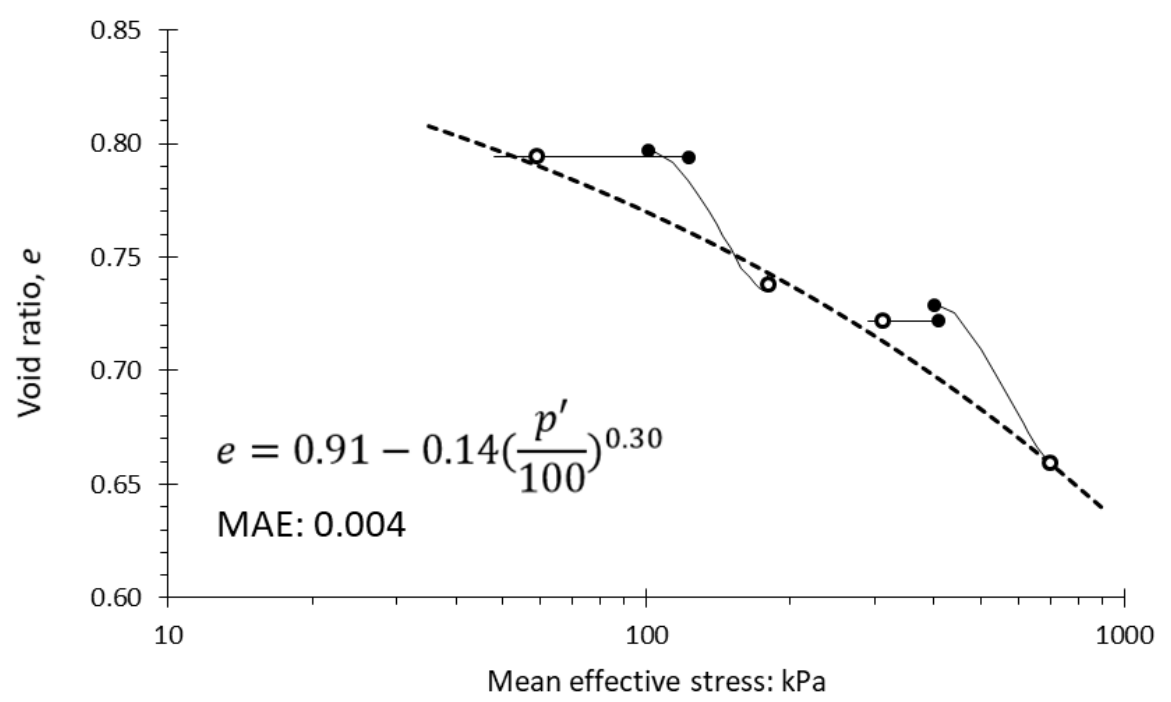

(b)

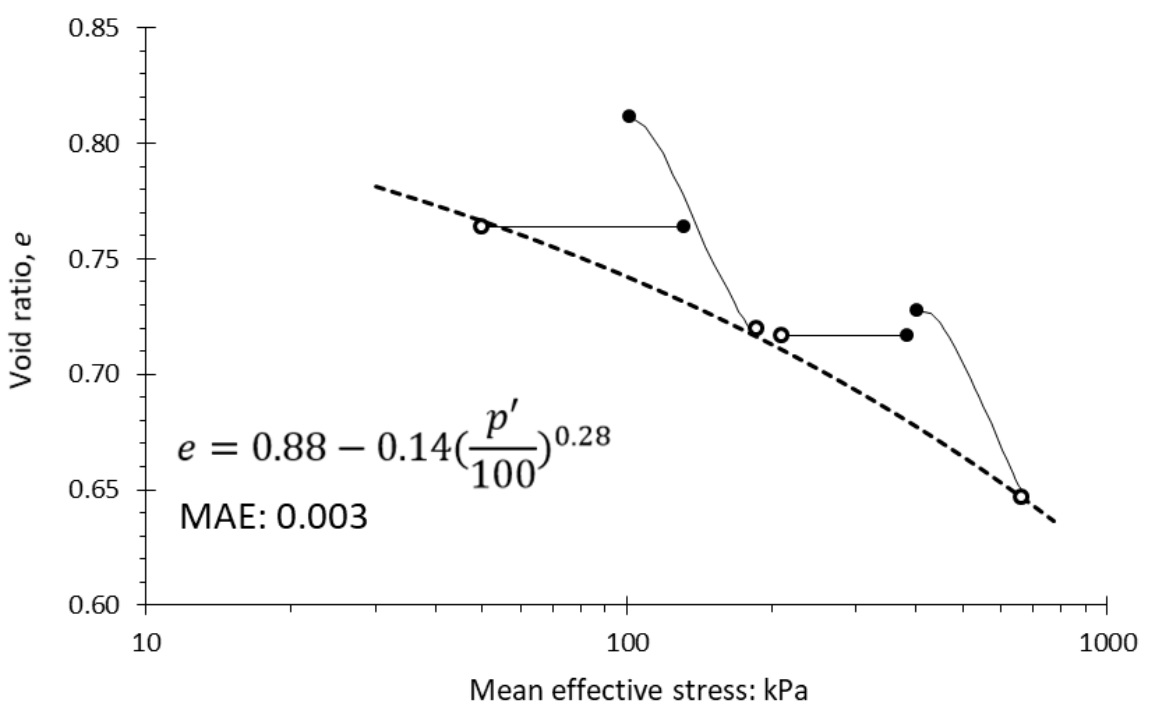

(c)

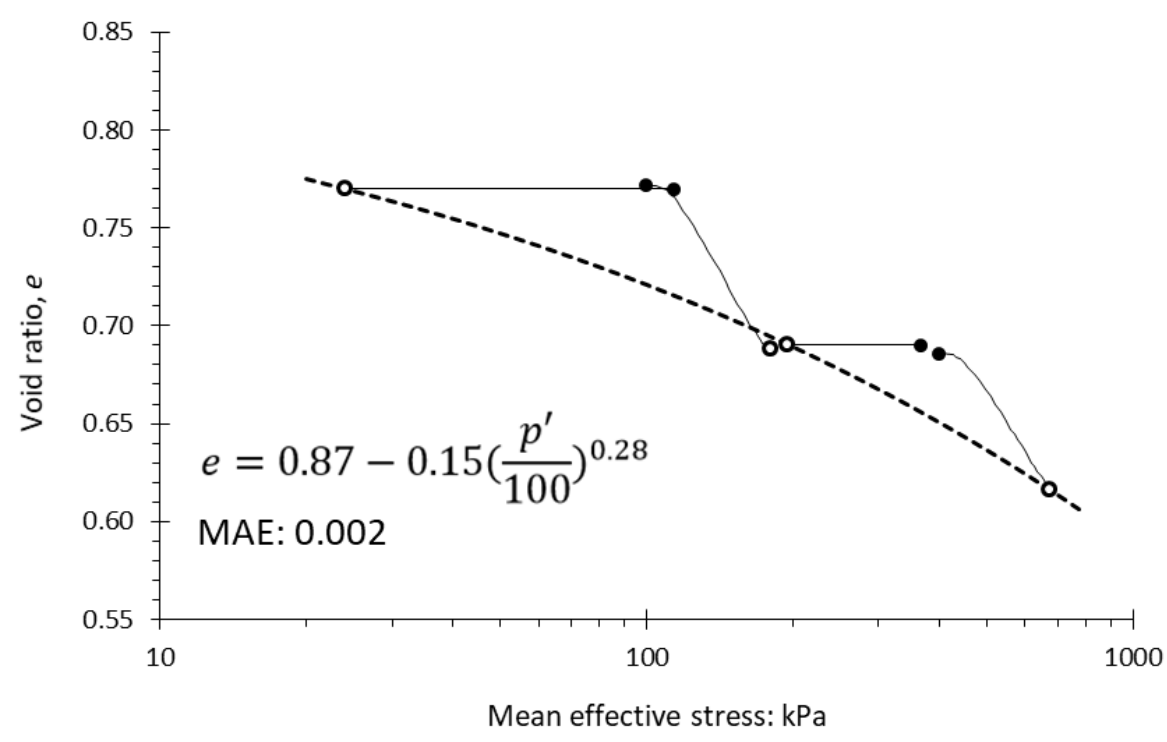

- Consolidated test state $\quad$ Inferred CS condition Inferred CSL

Figure 7: High salt sample state plots: (a) Sample A; (b) Sample B; (c) Sample C 
(a)

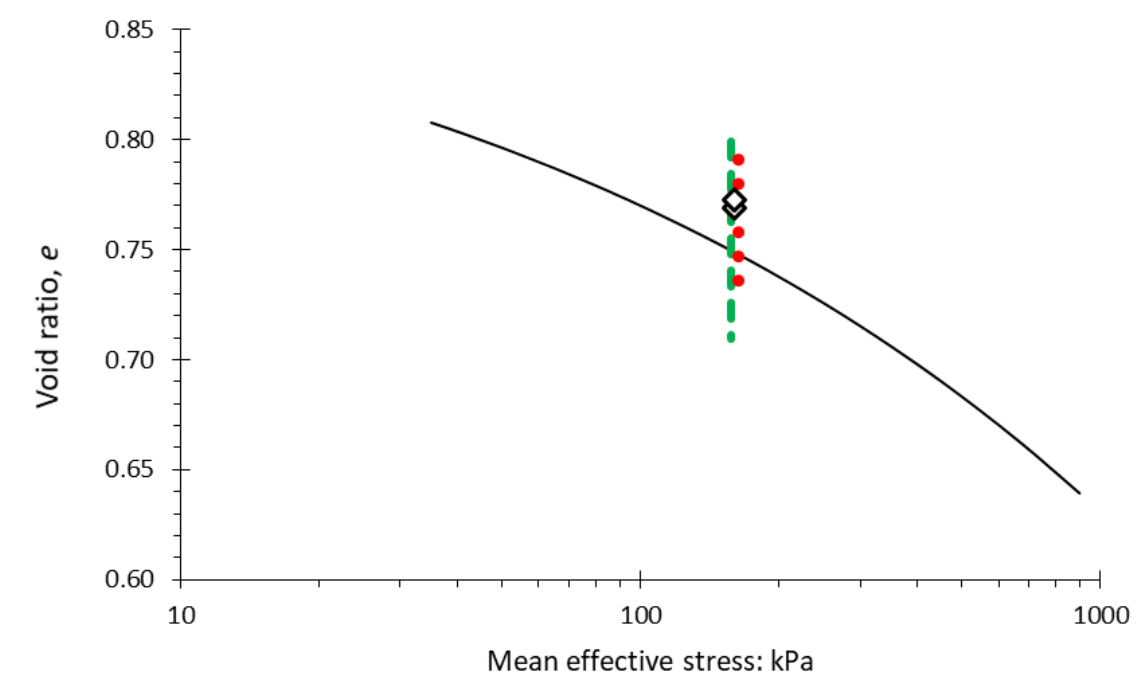

(b)

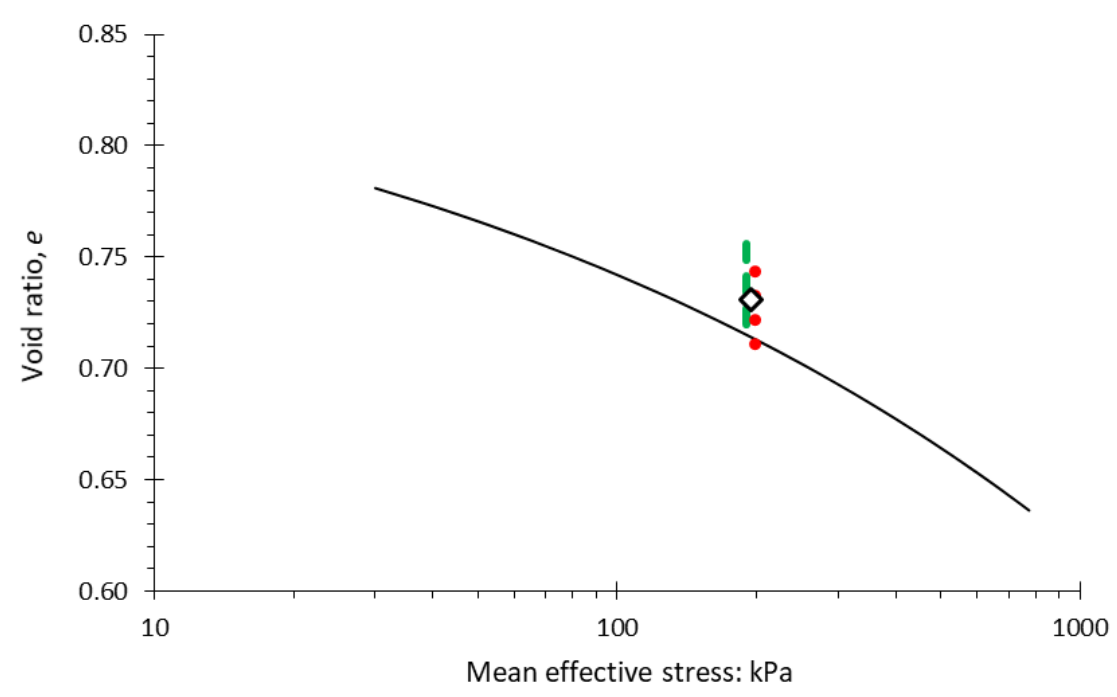

(c)

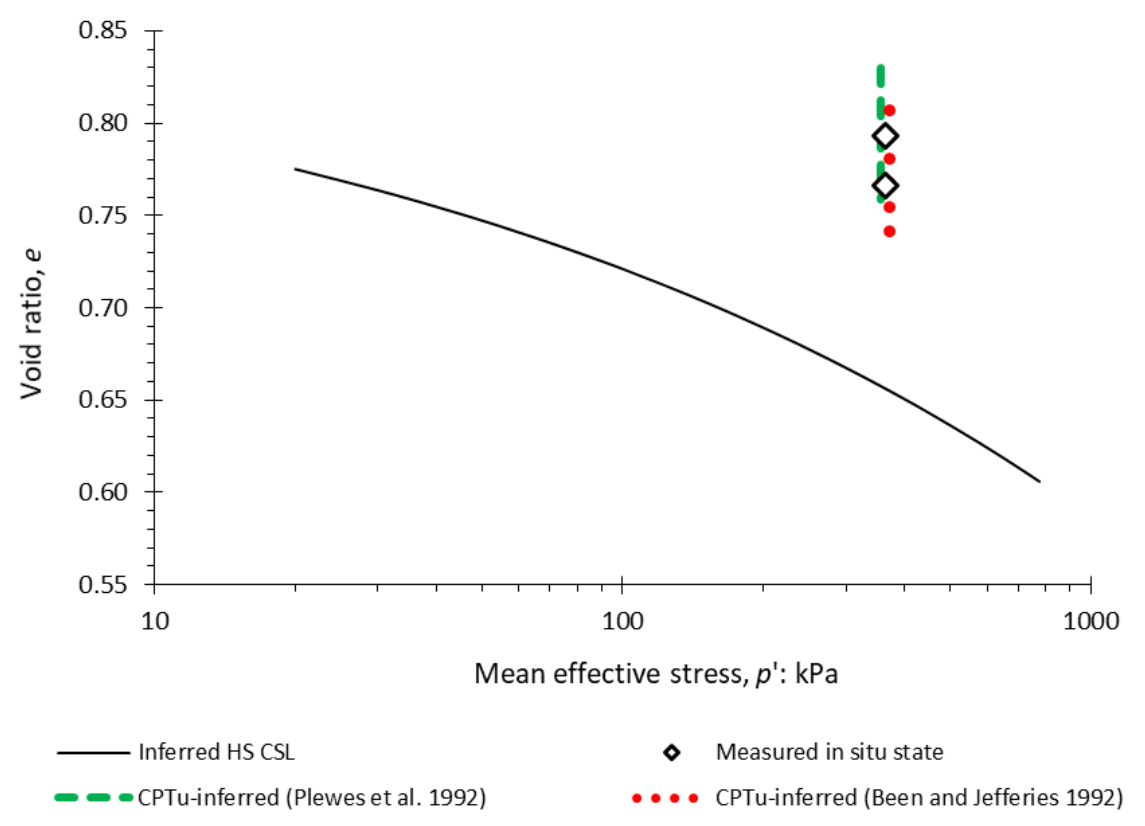

Figure 8: In situ state estimates compared to HS CSL: (a) Sample A; (b) Sample B; (c) Sample C 

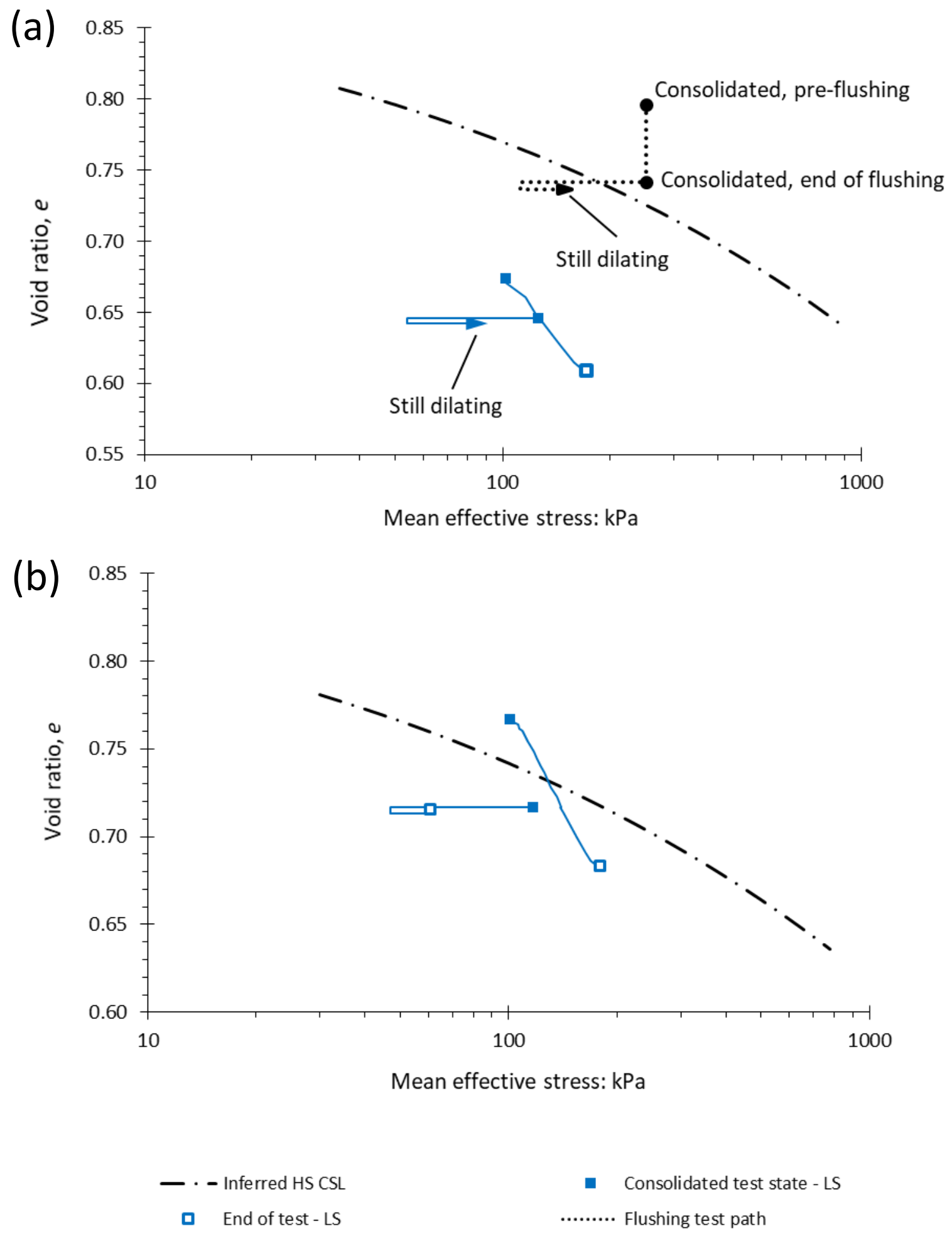

Figure 9: HS CSL compared to low salt tests and flushing test: (a) Sample A; (b) Sample B 
Table 1: Pore fluid constituents

\begin{tabular}{|l|c|}
\hline Constituent & $\begin{array}{l}\text { \% of total TDS, by } \\
\text { mass }\end{array}$ \\
\hline $\mathrm{Al}$ & $0.1 \%$ \\
\hline $\mathrm{Ca}$ & $3.4 \%$ \\
\hline $\mathrm{Cl}$ & $52.5 \%$ \\
\hline $\mathrm{CO} 3$ & $0.0 \%$ \\
\hline $\mathrm{HCO} 3$ & $0.0 \%$ \\
\hline $\mathrm{K}$ & $0.5 \%$ \\
\hline $\mathrm{Mg}$ & $1.0 \%$ \\
\hline $\mathrm{Mn}$ & $0.0 \%$ \\
\hline $\mathrm{Na}$ & $26.1 \%$ \\
\hline $\mathrm{NH} 3$ & $0.0 \%$ \\
\hline $\mathrm{NO} 2$ & $0.0 \%$ \\
\hline $\mathrm{NO} 3$ & $0.0 \%$ \\
\hline $\mathrm{SO} 4$ & $3.7 \%$ \\
\hline
\end{tabular}


Table 2: Summary of inferred stress history, state, and structure from CPTu-based methods

\begin{tabular}{|c|c|c|c|c|}
\hline Parameter & Estimation Method & Sample A & Sample B & Sample C \\
\hline $\begin{array}{l}\text { Vertical effective } \\
\text { stress, } \sigma^{\prime}{ }_{\text {vo }}(\mathrm{kPa})\end{array}$ & - & 187 & 228 & 450 \\
\hline$K_{\mathrm{G}}$ & Robertson (2016) & 316 & 273 & 244 \\
\hline OCR & Mayne et al. (2014 & 2.22 & 1.83 & 0.96 \\
\hline$\psi$ & Plewes et al. (1992) & +0.004 & +0.024 & +0.150 \\
\hline
\end{tabular}


Table 3: TDS and index properties

\begin{tabular}{|c|c|c|c|}
\hline Sample & A & B & C \\
\hline Adjacent CPTu probe & 1 & 1 & 2 \\
\hline Deposition type & Subaerial & Subaerial & Subaqueous \\
\hline Sample depth (m) & $15.5-16.0$ & $20.5-21.0$ & $26.0-26.5$ \\
\hline Specific Gravity, $G_{\mathrm{s}}$ & 2.54 & 2.63 & 2.57 \\
\hline Liquid Limit (\%) & 29 & 32 & 27 \\
\hline Plastic Limit (\%) & 18 & 19 & 18 \\
\hline Plasticity Index (\%) & 11 & 13 & 9 \\
\hline$\%<75$ um (wet sieve) & 82 & 86 & 80 \\
\hline$\%<38$ um (wet sieve) & 67 & 75 & 62 \\
\hline$\%<2$ um (Hydrometer) & 16 & 18 & 12 \\
\hline Activity & 0.69 & 0.72 & 0.75 \\
\hline & $\mathrm{T} 1-160$ & $\mathrm{~T} 1-140$ & \\
\hline Mass concentration salt (g/L) & $\mathrm{T} 2-169$ & $\mathrm{~T} 2-142$ & $\mathrm{~T} 1-120$ \\
& $\mathrm{~T} 3-179$ & $\mathrm{~T} 3-148$ & $\mathrm{~T} 2-131$ \\
\hline No. of tubes recovered & 4 & 4 & 2 \\
\hline No. of tubes used to calculate $e$ & 1 & 1 & 2 \\
\hline Void ratio from tubes & $\mathrm{T} 3-0.750$ & $\mathrm{~T} 4-0.768$ & $\mathrm{~T} 1-0.792$ \\
\hline "Moist" sample mass available $(\mathrm{kg})$ & 6.4 & 5.1 & 3.3 \\
\hline
\end{tabular}




\section{Pơg 49 of 51}

.

這

]

青

닐

Table 4: Summary of XRD results, percentage of dominant minerals

\begin{tabular}{|c|c|c|c|}
\hline Mineral type & Sample A & Sample B & Sample C \\
\hline Quartz & $69 \%$ & $65 \%$ & $72 \%$ \\
\hline Muscovite & $20 \%$ & $25 \%$ & $18 \%$ \\
\hline Dolomite & $11 \%$ & $11 \%$ & $10 \%$ \\
\hline
\end{tabular}


Table 5: Triaxial test summary

\begin{tabular}{|c|c|c|c|c|c|c|c|c|c|c|c|c|}
\hline \multirow[b]{2}{*}{ Sample } & \multicolumn{2}{|c|}{ Test details } & \multicolumn{4}{|c|}{ Consolidation conditions } & \multicolumn{4}{|c|}{ Inferred critical state conditions } & \multirow{2}{*}{$\begin{array}{l}\text { Triaxial end- } \\
\text { of-test TDS } \\
(\mathrm{g} / \mathrm{L})\end{array}$} & \multirow{2}{*}{$\begin{array}{l}\text { In situ TDS } \\
(\mathrm{g} / \mathrm{L})\end{array}$} \\
\hline & Test & Test type & $\begin{array}{c}p_{c}^{\prime} \\
(\mathrm{kPa})\end{array}$ & $\begin{array}{c}q_{\mathrm{c}} \\
(\mathrm{kPa})\end{array}$ & $K_{0}(-)$ & $e_{\mathrm{c}}(-)$ & $\begin{array}{l}p_{\mathrm{cs}}^{\prime} \\
(\mathrm{kPa})\end{array}$ & $\begin{array}{c}q_{\mathrm{cs}} \\
(\mathrm{kPa})\end{array}$ & $M_{\mathrm{tc}}(-)$ & $e_{c s}(-)$ & & \\
\hline \multirow{7}{*}{ A } & A-HS-1 & $\mathrm{CK}_{0} \mathrm{U}$ & 123 & 69 & 0.59 & 0.794 & 59 & 82 & 1.39 & 0.794 & 203 & \multirow{7}{*}{$160-185$} \\
\hline & A-HS-2 & $\mathrm{CID}$ & 401 & 3 & 0.99 & 0.729 & 703 & 991 & 1.41 & 0.659 & 213 & \\
\hline & A-HS-3 & $\mathrm{CK}_{0} \mathrm{U}$ & 409 & 327 & 0.48 & 0.722 & 335 & 465 & 1.39 & 0.722 & 207 & \\
\hline & A-HS-4 & $\mathrm{CID}$ & 101 & 2 & 0.98 & 0.797 & 183 & 250 & 1.37 & 0.735 & 201 & \\
\hline & A-LS-1 & $\mathrm{CK}_{0} \mathrm{U}$ & 126 & 81 & 0.55 & 0.644 & \multicolumn{4}{|c|}{ - } & $\sim 5$ & \\
\hline & A-LS-2 & $\mathrm{CID}$ & 101 & 4 & 0.96 & 0.674 & 171 & 217 & 1.27 & 0.609 & $\sim 5$ & \\
\hline & A-Flush-1 & $\mathrm{CIU}$ & 251 & 3 & 0.99 & 0.739 & \multicolumn{4}{|c|}{ - } & 3 & \\
\hline \multirow{6}{*}{ B } & B-HS-1 & $\mathrm{CK}_{0} \mathrm{U}$ & 131 & 93 & 0.52 & 0.764 & 50 & 69 & 1.38 & 0.764 & 166 & \multirow{6}{*}{$140-153$} \\
\hline & $\mathrm{B}-\mathrm{HS}-2$ & $\mathrm{CID}$ & 101 & 3 & 0.97 & 0.812 & 196 & 288 & 1.47 & 0.720 & 178 & \\
\hline & B-HS-3 & $\mathrm{CK}_{0} \mathrm{U}$ & 383 & 248 & 0.55 & 0.717 & 210 & 302 & 1.44 & 0.717 & 171 & \\
\hline & B-HS-4 & CID & 401 & 3 & 0.99 & 0.728 & 694 & 881 & 1.27 & 0.647 & 176 & \\
\hline & B-LS-1 & CID & 101 & 4 & 0.97 & 0.767 & 180 & 241 & 1.34 & 0.683 & $\sim 5$ & \\
\hline & B-LS-2 & $\mathrm{CK}_{0} \mathrm{U}$ & 117 & 53 & 0.65 & 0.715 & 61 & 76 & 1.25 & 0.715 & $\sim 5$ & \\
\hline \multirow{4}{*}{ C } & $\mathrm{C}-\mathrm{HS}-1$ & $\mathrm{CK}_{0} \mathrm{U}$ & 114 & 45 & 0.69 & 0.773 & 25 & 29 & 1.15 & 0.773 & 119 & \multirow{4}{*}{$120-131$} \\
\hline & $\mathrm{C}-\mathrm{HS}-2$ & $\mathrm{CID}$ & 101 & 4 & 0.96 & 0.772 & 189 & 266 & 1.41 & 0.688 & 122 & \\
\hline & $\mathrm{C}-\mathrm{HS}-3$ & CID & 402 & 5 & 0.99 & 0.686 & 697 & 891 & 1.28 & 0.616 & 122 & \\
\hline & C-HS-4 & $C K_{0} \mathrm{U}$ & 367 & 200 & 0.60 & 0.69 & 194 & 263 & 1.35 & 0.690 & 140 & \\
\hline
\end{tabular}




\section{Pagge 51 of 51}

Table 6: Comparison of different ion ratios in pore fluid

\begin{tabular}{|l|l|l|l|}
\hline Ratio & Reference & Decant water & $\begin{array}{l}\text { Triaxial specimens, after addition of } \\
\text { synthetic pore fluid }\end{array}$ \\
\hline $\mathrm{NaK}$ & Mitchell and Soga (2005) & 0.82 & 0.84 \\
\hline $\mathrm{KMgCa}$ & Helle et al. (2017) & 0.17 & 0.23 \\
\hline
\end{tabular}

